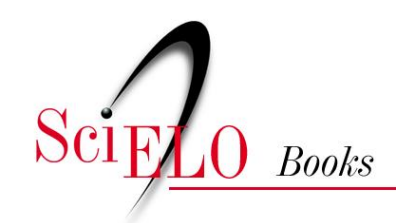

\{ิ의

FIOCRUZ

İpea $a_{\text {Econonomica Aplicada }}^{\text {Intita }}$ Ministério da

Secretaria de

Assuntos Estratégicos

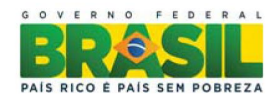

\title{
O subsistema de base mecânica, eletrônica e de materiais do complexo econômico industrial da saúde
}

perspectivas para 2022/2030

\author{
José Maldonado \\ Carlos A. Grabois Gadelha \\ Marco Vargas \\ Laís Silveira Costa \\ Cristiane Quental
}

\section{SciELO Books / SciELO Livros / SciELO Libros}

MALDONADO, J., et al. Indústrias de base química e biotecnológica voltadas para a saúde no Brasil: panorama atual e perspectivas para 2030. In FUNDAÇÃO OSWALDO CRUZ. A saúde no Brasil em 2030 - prospecção estratégica do sistema de saúde brasileiro: desenvolvimento produtivo e complexo da saúde [online]. Rio de Janeiro: Fiocruz/Ipea/Ministério da Saúde/Secretaria de Assuntos Estratégicos da Presidência da República, 2013. Vol. 5. pp. 81-117. ISBN 978-85-8110-019-7. Available from SciELO Books <http://books.scielo.org>.

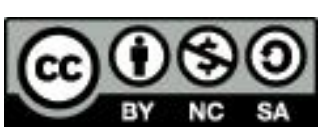

All the contents of this chapter, except where otherwise noted, is licensed under a Creative Commons Attribution-Non Commercial-ShareAlike 3.0 Unported.

Todo o conteúdo deste capítulo, exceto quando houver ressalva, é publicado sob a licença Creative Commons Atribuição Uso Não Comercial - Partilha nos Mesmos Termos 3.0 Não adaptada.

Todo el contenido de este capítulo, excepto donde se indique lo contrario, está bajo licencia de la licencia Creative Commons Reconocimento-NoComercial-CompartirIgual 3.0 Unported. 


\section{O Subsistema de Base Mecânica,}

Eletrônica e de Materiais do

Complexo Econômico Industrial da Saúde:

perspectivas para 2022/2030 


\title{
O SUBSISTEMA DE BASE MECÂNICA, ELETRÔNICA E DE MATERIAIS DO COMPLEXO ECONÔMICO INDUSTRIAL DA SAÚDE: PERSPECTIVAS PARA 2022 / 2030
}

\author{
José Maldonado \\ Carlos A. Grabois Gadelha \\ Marco Vargas \\ Laís Silveira Costa \\ Cristiane Quental
}

\section{PANORAMA GLOBAL}

A indústria de equipamentos e materiais médico-hospitalares e odontológicos, como é comumente denominado o subsistema de base mecânica, eletrônica e de materiais, tem um papel de destaque no âmbito do Complexo EconômicoIndustrial da Saúde, tanto pelo seu potencial de inovação - incorpora fortemente os avanços associados ao paradigma microeletrônico - quanto pelo seu impacto nos serviços, representando uma fonte constante de mudanças nas práticas assistenciais, trazendo permanentemente para o debate a tensão entre a lógica da indústria e a sanitária.

Esta indústria é fortemente associada às práticas médicas, determinando muitas vezes a tecnologia incorporada nos procedimentos adotados, no que se refere à prevenção, diagnóstico e tratamento de doenças. Possui, ademais, grande heterogeneidade tecnológica, incorporando segmentos bastante diversificados, desde bens de capital de alta complexidade (como diagnóstico por imagem) até materiais de consumo de uso rotineiro, passando por instrumentos, material cirúrgico e ambulatorial, seringas, entre muitos outros exemplos.

A indústria deste subsistema se caracteriza por ser um oligopólio ${ }^{1}$ baseado na diferenciação de produtos e no fornecimento de bens, em grande parte altamente especializados, com grande quantidade de produtos sendo lançados continuamente, com novas opções de tratamento e diagnóstico, com ciclos tecnológicos curtos (com

1 De acordo com ABDI (2009a), as 20 maiores empresas respondem por aproximadamente 70\% da produção mundial. 
duração de menos de dois anos), e que são comercializados em associação com serviços e outros produtos (LEÃO et al., 2008). A diferenciação de produtos se baseia na intensidade dos gastos em $\mathrm{P} \& \mathrm{D}$ e a natureza dos conhecimentos que incorpora assenta-se fortemente nas ciências físicas de base mecânica e eletrônica e em avanços tecnológicos oriundos de outras indústrias tradicionalmente inovadoras, a exemplo da microeletrônica, mecânica de precisão, química e novos materiais (GADELHA, 2007).

A tabela 1 apresenta para 2009 as 10 empresas que mais investem em P\&D na indústria, especificando para cada uma o montante investido, o crescimento percentual dos últimos quatro anos, o percentual sobre vendas e o crescimento percentual médio das vendas nos últimos quatro anos.

Tabela 01. Empresas que mais investem em P\&D na indústria, 2009

\begin{tabular}{l|c|c|c|c|c}
\multicolumn{1}{c|}{ Empresa } & País & $\begin{array}{r}\text { Inv. P\&D } \\
(£ \text { milh. })\end{array}$ & $\begin{array}{c}\% \text { cresc. últ. } \\
4 \text { anos }\end{array}$ & $\begin{array}{c}\% \text { das } \\
\text { vendas }\end{array}$ & $\begin{array}{c}\text { \% cresc. médio de } \\
\text { vendas últ. 4 anos }\end{array}$ \\
\hline Meditronic & EUA & 942,41 & 18,0 & 9,3 & 24,0 \\
\hline Boston Scientific & EUA & 699,68 & 20,0 & 12,5 & 15,0 \\
\hline Baxter International & EUA & 603,70 & 43,0 & 7,0 & 20,0 \\
\hline Saint Jude Medical & EUA & 369,87 & 36,0 & 12,2 & 42,0 \\
\hline Carl Zeiss & DE & 310,33 & 31,0 & 11,8 & 16,0 \\
\hline Becton Dickinson & EUA & 275,59 & 29,0 & 5,5 & 27,0 \\
\hline Stryker & EUA & 255,81 & 24,0 & 5,5 & 31,0 \\
\hline Covidian & EUA & 237,17 & n.d. & 3,2 & n.d. \\
\hline Fresenius & DE & 200,12 & 31,0 & 1,7 & 32,0 \\
\hline Beckman Coulter & EUA & 194,81 & 18,0 & 9,0 & 22,0 \\
\hline
\end{tabular}

n.d. - não disponível.

Fonte: The 2009 R\&D Scoreboard, 2010.

Entre as empresas que desenvolvem os maiores esforços de inovação, os gastos em P\&D, com exceção da Covidian e da Fresenius, situam-se entre 12\% e 6\% das vendas. Constata-se a forte presença de empresas norte-americanas dentre aquelas que mais investem em $\mathrm{P} \& \mathrm{D}$, em função, inclusive, de características do mercado norteamericano detalhadas adiante. Em um ambiente crescentemente competitivo, além da atividade formal de $\mathrm{P} \& \mathrm{D}$, as empresas desenvolvem outras estratégias de apropriação de conhecimento, seja na forma de acordos de colaboração, seja em processos interativos com outros agentes socioeconômicos - fusões e aquisições, alianças (joint-ventures, acordos de P\&D, acordos de marketing) e acordos de financiamento (PAMMOLLI, 2005). 
Apesar da forte intensidade de P\&D que caracteriza a indústria, em alguns segmentos de menor complexidade tecnológica como é o caso do mercado de seringas, luvas e equipamentos de diagnósticos mais convencionais, o padrão de competição se baseia em preços, no qual a produção e os ganhos de competitividade estão vinculados à escala e as margens de lucro são mais reduzidas (LEÃO et al., 2008).

De acordo com Gutierrez e Alexandre (2004), a indústria de equipamentos e materiais médico-hospitalares e odontológicos tem apresentado um dinamismo significativo nos últimos anos decorrente: da incorporação de avanços tecnológicos, que tem significado o constante desenvolvimento de novos produtos com novas funções; do envelhecimento da população, sobretudo nos países desenvolvidos, que tem promovido a ampliação da demanda por serviços de saúde; e do crescimento do mercado, especialmente dos países em desenvolvimento, decorrentes da reformulação dos sistemas de saúde e (ou) dos aumentos dos gastos em saúde.

A ampliação da demanda e dos serviços de saúde e o próprio desenvolvimento tecnológico da indústria estão estreitamente ligados. De um lado, as empresas, ao disponibilizarem novos equipamentos, direcionam a demanda dos serviços da saúde no sentido da incorporação destes novos equipamentos e tratamentos alternativos. Por outro lado, esta incorporação retroalimenta o processo de inovação das empresas ao impor melhorias sucessivas nos equipamentos. Ou seja, a esfera do consumo detém também um papel crucial no processo inovativo das empresas.

Neste sentido, Albuquerque e Cassiolato (2000) ao destacarem que o desenvolvimento tecnológico na indústria de equipamentos e materiais médicohospitalares e odontológicos é fortemente incremental, salientam que o processo de inovação não ocorre somente nos laboratórios industriais, mas também na prática clínica, uma vez que é nela que se identifica a necessidade e a possibilidade de um novo equipamento, a criação do primeiro protótipo e aprimoramentos decisivos para o desenvolvimento do equipamento.

Castro (2003), por sua vez, ao destacar a extrema rapidez do processo de difusão tecnológica na saúde, ressalta que as tecnologias da área não são substitutivas e sim, complementares e cumulativas. Neste sentido, exemplifica que a utilização da ressonância magnética não excluiu o uso da tomografia computadorizada em testes de diagnóstico, antibióticos não substituíram os anti-inflamatórios e a ultrassonografia não eliminou o uso do raio X.

O desenvolvimento de novas tecnologias e novos tratamentos cada vez mais aperfeiçoados e mais caros, o caráter cumulativo da utilização das tecnologias que significa o uso de um maior número de equipamentos e o concomitante aumento dos custos de manutenção, e a ampliação dos serviços de saúde, em conjunto, têm significado uma crescente magnitude dos gastos com serviços de saúde. 
Entretanto, crescentes pressões pelo controle dos gastos públicos e privados na saúde em nível mundial em virtude da crescente demanda por serviços de saúde vêm pressionando as empresas a focarem seus desenvolvimentos tecnológicos levando em conta não somente o aumento da qualidade dos padrões de tratamento e diagnóstico das novas tecnologias, mas também sua capacidade de redução do custo dos tratamentos. Neste sentido, eficiência e custo na esfera da utilização destes equipamentos passaram a ser parâmetros determinantes nos avanços tecnológicos das empresas da indústria.

O mercado mundial destes equipamentos em 2009 era avaliado em US\$ 234 bilhões (The World Medical Markets Fact Book, 2010), sendo que as projeções indicam que este mercado deverá apresentar um crescimento de mais de $8 \%$ a.a. nos próximos cinco anos, chegando a um patamar de US\$ 490 bilhões em 2016 (PARTNERING NEWS, 2011). O gráfico 1 apresenta a participação por região no mercado mundial em 2009. A tabela 2, por sua vez, apresenta para este ano a participação no mercado mundial, em valor e percentual, por principais países.

A partir das informações contidas no gráfico 1 e na tabela 2, constata-se a forte concentração da indústria nos países da tríade. Os EUA representam inconteste o maior mercado mundial com praticamente $40 \%$ do total. EUA, Japão, Alemanha, França, Itália e Grã-Bretanha detêm em conjunto 68,2\% do total mundial em 2009. Os designados BRIC - Brasil, Rússia, Índia e China, em conjunto representam $6,73 \%$ do total, com a China e a Rússia ocupando a $7^{\circ}$ e a $9^{\circ}$ posição, respectivamente, em termos de participação no mercado mundial.

Gráfico 01. Distribuição percentual do mercado mundial por região, 2009

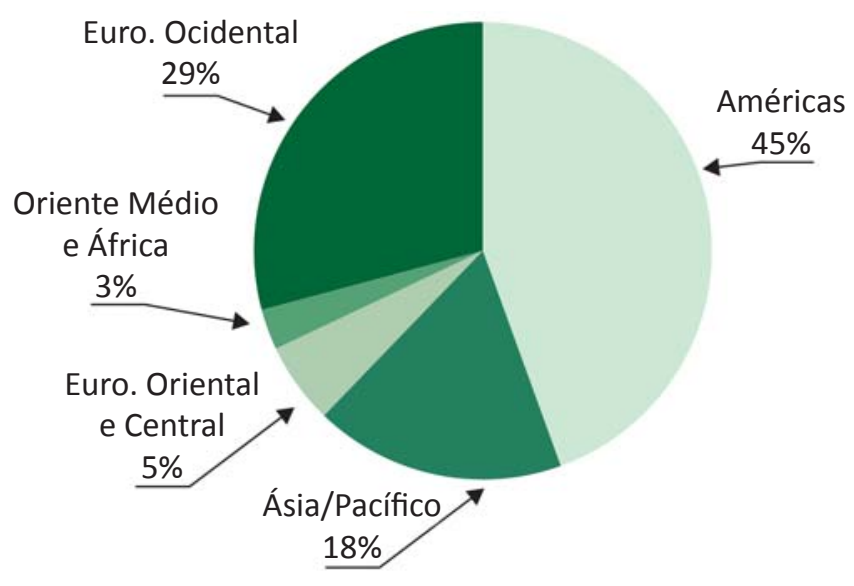

Fonte: The World Medical Markets Fact Book, 2010. 
Tabela 02. Participação no mercado mundial por principais países, 2009

\begin{tabular}{rl|c|c}
\multicolumn{1}{c|}{ País } & US\$̦ milhões & $\%$ \\
\hline 1 & EUA & 92.662 & 39,7 \\
\hline 2 & Japão & 21.713 & 9,3 \\
\hline 3 & Alemanha & 18.843 & 8,1 \\
\hline 4 & França & 9.071 & 3,9 \\
\hline 5 & Itália & 8.703 & 3,7 \\
\hline 6 & Grã-Bretanha & 8.284 & 3,5 \\
\hline 7 & China & 6.695 & 2,9 \\
\hline 8 & Canadá & 4.922 & 2,1 \\
\hline 9 & Rússia & 4.913 & 2,1 \\
\hline 10 & Espanha & 4.257 & 1,8 \\
\hline 17 & Brasil & 2.219 & 0,9 \\
\hline 19 & Índia & 1.986 & 0,8 \\
\hline & Outros & 49.382 & 21,2 \\
\hline & Total & $\mathbf{2 3 3 . 6 5 0}$ & 100,0 \\
\hline
\end{tabular}

Fonte: The World Medical Markets Fact Book, 2010.

O mesmo padrão de concentração da participação no mercado mundial ocorre para o comércio exterior, com destaque para a participação norte-americana. Os 10 principais países em conjunto contavam em 2009 com 66,4\% das importações mundiais (EUA, Alemanha, Holanda, França, Japão, Bélgica, Grã-Bretanha, Itália, China e Canadá em ordem decrescente de importância) e eram responsáveis por 78,5\% das exportações mundiais (EUA, Alemanha, Holanda, França, Irlanda, Suíça, Bélgica, China, Grã-Bretanha e Japão em ordem decrescente de importância). Praticamente os maiores importadores são também os maiores exportadores. Os EUA respondem respectivamente, por $19,0 \%$ e $22,7 \%$ das importações e exportações mundiais. No âmbito dos BRIC, ressalte-se a posição relativa da China que em 2009 era o $9^{\circ}$ maior importador e o $8^{\circ}$ maior exportador. No seu conjunto, estes países respondiam em 2009 com respectivamente, 7,6\% e 5,2\% das importações e exportações mundiais (ESPICOM BUSINESS INTELLIGENCE, 2010).

A forte presença norte-americana é ainda sentida ao se considerar as maiores empresas da indústria em termos da receita de vendas. Na relação dos 20 maiores fabricantes mundiais 16 são empresas norte-americanas (SELAN et al., 2007). De acordo com Leão et al. (2008), o sucesso das empresas norte-americanas 
nesta indústria é resultado da convergência de um conjunto de fatores: ambiente institucional e empresarial no qual as empresas estão inseridas, a extensão do mercado privado dos serviços de saúde com ampla capacidade de absorção de uma oferta crescente de novos produtos, forte atuação do governo na abertura e acesso a novos mercados e o engajamento tradicional das empresas em P\&D. A existência de indústrias correlatas como a microeletrônica, telecomunicações, instrumentação, biotecnologia, desenvolvimento de software, entre outras, completa esta perspectiva (SELAN et al., 2007).

O tamanho do mercado nacional, a forte participação no comércio exterior e o porte das empresas, fazem dos EUA o grande player da indústria. Possuindo cadeias produtivas em todos os segmentos, os investimentos norte-americanos no exterior visam ampliar suas participações nos principais mercados consumidores (sobretudo, Europa e Japão), enquanto que o principal critério locacional dos investimentos europeus e japoneses em relação ao mercado norte-americano é a proximidade com o polo mundial dominante da indústria².

Por não possuírem a mesma capacidade tecnológica e industrial, os demais países concorrentes, especialmente os europeus e o Japão, desenvolvem estratégias de especialização e de segmentação. A Alemanha, por exemplo, procurou se especializar no segmento de diagnóstico por imagem, cuja principal empresa é a Siemens, e no de implantes. O Japão, por sua vez, se destaca principalmente em aparelhos de ultrassonografia, aparelhos de eletrodiagnóstico e de instrumentos oftálmicos. Toshiba Medical, Shimadzu e Hitachi se destacam como as grandes empresas japonesas, detendo em conjunto, 70\% do mercado japonês (SELAN et al., 2007).

A liderança do mercado mundial é exercida indubitavelmente por grandes empresas, que estabelecem o padrão e o ritmo de incorporação tecnológica da indústria e que, crescentemente, vêm adotando estratégias de integração de suas atividades comerciais e industriais em nível global ${ }^{3}$. A descentralização mundial das atividades produtivas destas empresas se dá tanto por meio do investimento externo direto como por fusões e aquisições.

No primeiro caso, o investimento externo vem-se desdobrando no estabelecimento da oferta de soluções integradas, isto é, produtos associados a serviços: rede de prestação de serviços técnicos, de assistência e manutenção, programas de

2 Furtado (2001) sugere que o predomínio das empresas norte-americanas é ainda superior ao que as estatísticas de comércio exterior revelam, uma vez que parte da produção mundial é oriunda de suas subsidiárias no exterior.

3 Em termos de estrutura organizacional assiste-se a dois movimentos distintos: enquanto algumas empresas têm suas atividades de produção estruturadas em um sistema de integração vertical em nível global, outras adotam estratégias de desverticalização, mediante processos de terceirização, subcontratação, ou parcerias para suas atividades de produção. A Siemens se enquadra no primeiro caso, enquanto a Philips no segundo (GOMES, 2007). 
software e serviços financeiros. O uso destes equipamentos, de um modo geral, está associado à necessidade de reposição de insumos, de peças ou de produtos químicos o que, ao reforçar os custos de mudança, também gera uma dependência prolongada entre fornecedores e consumidores. Marca, reputação, confiança e qualidade dos produtos e serviços são outros ativos complementares que promovem a fidelização dos usuários $^{4}$. Estas estratégias de comercialização das grandes empresas vêm significando um aumento das barreiras à entrada nos segmentos nos quais elas se instalam nos países hospedeiros, impedindo ou mesmo excluindo as empresas de menor porte que não dispõem de recursos maiores.

No segundo caso, o processo de aquisições e fusões na indústria tem sido intenso nos últimos anos; entre 2006 e 2009, este processo movimentou cerca de US\$ 25 bilhões (BUSINESS WIRE, 2011). Este movimento, liderado pelas principais empresas mundiais, objetiva a ampliação de escalas de produção e concomitante redução de custos, principalmente os custos fixos intangíveis, como custos de promoção de vendas e os custos de desenvolvimento de novos produtos. No caso das aquisições, as adquirentes ganham acesso instantâneo a novos produtos, novos clientes e a uma infraestrutura de vendas e de assistência técnica, e ampliam seu poder de negociação com os compradores.

Cabe destacar que as empresas farmacêuticas têm manifestado crescente interesse nesta indústria, no âmbito de estratégias de diversificação de seus investimentos, face aos desafios enfrentados pela perda de dinamismo relativo das designadas economias farmacêuticas maduras. O cenário de crise financeira de 2009 tornou-se propício ao movimento de concentração da indústria ao causar retração da disponibilidade de recursos para a realização de investimentos e redução da demanda pelos mais diversos tipos de produtos e equipamentos médicos (ABDI, 2009a).

Ainda do ponto de vista da internacionalização da produção, assiste-se ao crescente interesse por parte das multinacionais nos mercados emergentes, em função de suas taxas de crescimento, da ampliação de seus sistemas nacionais de saúde, da extensão da cobertura das redes de assistência e da expansão dos gastos públicos em saúde. Dentre estes, os BRIC têm papel de destaque, salientando-se que já em 2006, o conjunto de dispêndios em saúde destes países foi igual ao da Alemanha, de cerca de US $\$ 266$ bilhões. Em que pese suas diferenças relativas, os quatros países, do ponto de vista de investidores externos, possuem os seguintes pontos positivos em comum: população urbanizada com crescente poder de compra; dinamismo econômico e

4 Teece (1992) destaca o papel dos ativos complementares como instrumentos importantes de apropriação dos resultados dos esforços de $\mathrm{P} \& \mathrm{D}$. A este título, exemplifica com a EMI, empresa britânica que criou e lançou o tomógrafo, mas foi incapaz de se apropriar dos resultados oriundos de sua inovação. Em pouco tempo, duas imitadoras, GE e Technicare, empresas com longa experiência na indústria de equipamentos médicohospitalares, o que não era o caso da EMI, e que possuíam ativos complementares estratégicos, foram capazes de lançar seus próprios tomógrafos e, rapidamente, assumir a liderança deste segmento. 
perspectivas de crescimento; indústria local de baixa e média intensidade tecnológica; e dependência de importações, sobretudo, de itens de maior complexidade tecnológica (SELAN et al., 2007).

Relativamente ao perfil empresarial, as grandes empresas predominam nos segmentos cujos produtos apresentam maior complexidade tecnológica e maior valor agregado. Contudo, verifica-se também uma forte presença de pequenas e médias empresas em atividades especializadas e segmentadas (GUTIERREZ e ALEXANDRE, 2004). Assim, do ponto de vista da política de desenvolvimento industrial e de inovação, mostra-se factível a entrada de países menos desenvolvidos em certos nichos de mercado e a concepção de estratégias empresariais e nacionais de desenvolvimento focalizadas nestes segmentos, sejam máquinas, instrumentos ou bens de consumo de menor complexidade (GADELHA, 2007).

\section{2 | PANORAMA NACIONAL}

No Brasil, a indústria de equipamentos e materiais se estruturou no período 1950-1980 no esteio do modelo de substituição de importações, tendo progressivamente passado a ofertar instrumentos médicos, materiais de consumo e equipamentos eletrônicos de maior densidade tecnológica.

Contudo, a década de 1990 foi marcada por transformações estruturais no funcionamento desta indústria em decorrência do processo de abertura comercial, o que significou uma crescente dependência do país em relação às importações de equipamentos, sobretudo, de maior densidade tecnológica. Assim, uma série de produtos que havia sido incorporada à produção local nas décadas anteriores deixa de ser produzida no país, como por exemplo, marca-passos implantáveis e aparelhos de laboratório mais complexos, ou mesmo, equipamentos radiológicos cuja produção foi inteiramente desativada pelas multinacionais (MANFREDINI, 2006).

Entretanto, o crescimento da demanda interna provocada pelo Plano Real em paralelo à estruturação do Sistema Único de Saúde (SUS), que envolveu a ampliação da oferta de serviços com base nas diretrizes da universalização e integralidade e o aumento do peso da demanda pública neste mercado foi responsável pela significativa expansão da indústria a partir da segunda metade da década de 1990 (BUTTON, 2012). Nesta mesma direção, os programas de investimento do governo federal na rede assistencial responderam por parte expressiva no dinamismo empresarial, a exemplo do programa REFORSUS (já finalizado) e dos financiamentos do BNDES para a rede filantrópica, que viabilizaram a incorporação de equipamentos no sistema (GADELHA, 2007). 
O dinamismo recente da indústria pode ser constatado pelo crescimento de 37\% no número de empresas da indústria de 1999 a 2009 e de 307\% nas vendas nominais no mesmo período, o que descontada a inflação, representa uma evolução real de 114,3\% (IEMI, 2010). De acordo com a ABIMO, a indústria respondeu em 2009 por um faturamento de cerca de US\$ 4,28 bilhões, exportações de US\$ 541 milhões, sendo responsável pela geração de 32 mil empregos diretos e 72 mil empregos indiretos (ABIMO, 2010).

Existem no Brasil 448 empresas atuantes na indústria de equipamentos e materiais médico-hospitalares e odontológicos (IEMI, 2010). Em termos de origem do capital, 90,7\% das empresas são de capital nacional, 6,5\% são empresas estrangeiras e os restantes 2,8\% são de empresas de capital misto (ABIMO, 2010). Outra característica marcante é a concentração regional da indústria: 76\% das empresas localizam-se em São Paulo (capital 40\% e interior 36\%), em seguida está o Rio de Janeiro com 6\%, Paraná com 5,6\%, Minas Gerais com 4\% e o restante do país com 8\% das empresas (IEMI, 2010).

Além de estrutura bastante segmentada, a indústria congrega um grande número de empresas de pequeno e médio porte, com receitas inferiores a R\$ 50 milhões. As empresas grandes, embora representem 12\% do total, respondem pelos maiores percentuais em termos da mão de obra empregada, do faturamento e dos investimentos. Constata-se igualmente a predominância de empresas de porte médio, com $62 \%$ do total da indústria, especializadas, na sua maioria, nos segmentos de baixa e média densidade tecnológica (ABIMO, 2010). Muitas delas possuem formatos gerenciais inadequados para a competitividade, como estrutura familiar e baixo grau de profissionalização da gestão. Estes fatores explicam o afastamento da indústria da fronteira tecnológica no período recente, em termos dos grupos de produtos, a despeito do processo de expansão observado.

Deve-se salientar que as grandes empresas localizadas no país são, basicamente, subsidiárias das grandes multinacionais ${ }^{5}$ com atuação significativa no segmento de insumos e material de consumo que, nos últimos anos, têm respondido por quase a metade das exportações anuais da indústria do subsistema.

Estas empresas produzem e exportam a partir do Brasil e, portanto, estes investimentos ficam sujeitos às decisões estratégicas globais das grandes corporações. Como exemplo, cita-se a mudança do status do país que passou da condição de importador para exportador de pensos adesivos e suturas como resultado da decisão da Johnson \& Johnson de produzi-los e exportá-los a partir do Brasil há cerca de 10 anos atrás. Do mesmo modo, a decisão da BD\&Co de produzir e exportar agulhas a partir do Brasil inverteu a posição anterior de importador deste produto para exportador. Na direção contrária, o fechamento da unidade de São José dos Campos da Kodak,

5 Entre as empresas estrangeiras com atuação no Brasil incluem-se a GE, Philips, Toshiba, Siemens, Kodak, Shimadzu, Becton Dickinson, Baxter, Edwards Lifesciences, Johnson \& Johnson, 3M, Saint Jude e Fresenius (EXPORTMED BRAZIL, 2004). 
transformou o país da condição de exportador para importador de filmes radiológicos (ABDI, 2009b).

Pode-se considerar que a parcela dinâmica da indústria, em termos das taxas de crescimento dos últimos anos, atendimento da demanda interna, exportações sustentáveis e maior conteúdo tecnológico relativo, se situa nos segmentos de equipamentos médico-hospitalares (por exemplo, monitores de sinais vitais multiparamétricos, ventiladores pulmonares, incubadoras para recém nascidos, berços radiantes, equipamentos de fototerapia, esterilizadores médico-cirúrgicos, bombas de infusão, bisturis elétricos, equipamentos de mecanoterapia e fisioterapia, mesas cirúrgicas, focos cirúrgicos e camas hospitalares elétricas), implantes (por exemplo, próteses articulares, aparelhos biomecânicos para fraturas e válvulas cardíacas e odontológico) e odontológico (por exemplo, cimentos odontológicos e amálgamas, dentes artificiais de acrílico, equipamentos de uso odontológico, consultórios odontológicos, aparelhos dentários de brocar e aparelhos de raio X de acompanhamento odontológico). Os fabricantes destas famílias de produtos representam quase 40\% da produção nacional, inovam frequentemente suas linhas de produtos e alcançaram, nos últimos anos, uma presença relevante no mercado internacional (ABDI, 2009b).

Já nos segmentos de equipamentos e insumos para diagnóstico de imagem e laboratórios a fragilidade da indústria nacional é patente em termos de competitividade internacional, sendo que as empresas nacionais suprem menos da metade da demanda interna, fornecendo produtos de menor valor agregado (ABDI, 2009b). No segmento de radiologia, por exemplo, Pieroni et al. (2010) salientam que é o segmento mais afetado pela concorrência de produtos estrangeiros tendo havido nos últimos anos, inclusive, redução do número de empresas.

A tabela 3 apresenta a evolução de 2003 a 2008 do faturamento da indústria desagregado por segmento.

Tabela 03. Faturamento da indústria de equipamentos e materiais médico-hospitalares e odontológicos por segmento, 2003-2008

\begin{tabular}{l|r|r|r|r|r|r|c}
\hline \multicolumn{1}{c|}{ Segmento } & $\mathbf{2 0 0 3}$ & $\mathbf{2 0 0 4}$ & $\mathbf{2 0 0 5}$ & $\mathbf{2 0 0 6}$ & $\mathbf{2 0 0 6}$ & $\mathbf{2 0 0 8}$ & $\begin{array}{c}\text { Taxa de crescimento } \\
\text { anual composta (\%) }\end{array}$ \\
\hline Odontologia & 534 & 582 & 645 & 728 & 973 & 986 & 13,1 \\
\hline Laboratório & 586 & 618 & 663 & 768 & 769 & 808 & 6,6 \\
\hline Radiologia & 448 & 523 & 615 & 704 & 763 & 665 & 8,2 \\
\hline Equip. médicos & 957 & 1.006 & 1.076 & 1.115 & 1.238 & 1.279 & 6,0 \\
\hline Implantes & 516 & 565 & 630 & 731 & 778 & 777 & 8,6 \\
\hline Mat. de consumo & 1.832 & 2.063 & 2.354 & 2.682 & 2.760 & 2.762 & 8,6 \\
\hline
\end{tabular}

Fonte: Pieroni et al., 2010. 
Verifica-se uma majoração significativa da taxa anual de crescimento de todos os segmentos no período, não tendo ocorrido variações na participação dos diferentes segmentos no faturamento total da indústria. O segmento de material de consumo, cujos produtos são geralmente de baixo conteúdo tecnológico, detém a maior participação, com 37\% do faturamento total da indústria em 2008. A parcela referente a equipamentos médicos e odontológicos também é relevante com, respectivamente, $18 \%$ e $14 \%$ do total em 2008.

Para avaliar o potencial de inovação da indústria no período recente tomouse como base informações da Pesquisa Industrial de Inovação Tecnológica (PINTEC) 2000, 2003 e 2005, do IBGE. A tabela 4 apresenta os dispêndios em atividades inovativas da indústria de equipamentos e materiais médico-hospitalares e odontológicos, nos anos de 2000, 2003 e 2005.

Tabela 04. Dispêndios em atividades inovativas na indústria de equipamentos e materiais médicohospitalares e odontológicos, 2000/2003/2005

\begin{tabular}{l|c|c|c|c|c|c|c|c|c|}
\hline \multirow{2}{*}{ Tipo de atividade } & \multicolumn{3}{|c|}{2000} & \multicolumn{3}{c|}{2003} & \multicolumn{3}{c}{2005} \\
\cline { 2 - 10 } & $\begin{array}{c}\mathbf{N}^{\circ} \text { de } \\
\text { empr. }\end{array}$ & $\begin{array}{c}\text { Valor } \\
\text { (mil R\$̣) }\end{array}$ & $\begin{array}{c}\% \text { da } \\
\text { RLV* }\end{array}$ & $\begin{array}{c}\mathbf{N}^{\circ} \text { de } \\
\text { empr. }\end{array}$ & $\begin{array}{c}\text { Valor } \\
\text { (mil R\$̣) }\end{array}$ & $\begin{array}{c}\% \text { da } \\
\text { RLV* }\end{array}$ & $\begin{array}{c}\mathbf{N}^{\circ} \text { de } \\
\text { empr. }\end{array}$ & $\begin{array}{c}\text { Valor } \\
\text { (mil R\$) }\end{array}$ & $\begin{array}{c}\% \text { da } \\
\text { RLV* }\end{array}$ \\
\hline $\begin{array}{l}\text { Dispêndios em } \\
\text { ativ. Inovativas }\end{array}$ & 368 & 200.124 & 5,04 & 299 & 179.028 & 3,07 & 488 & 398.235 & 5,29 \\
\hline $\begin{array}{l}\text { Atividades } \\
\text { internas de P\&D }\end{array}$ & 204 & 70.292 & 1,77 & 202 & 71.269 & 1,22 & 319 & 170.331 & 2,26 \\
\hline
\end{tabular}

*RLV — receita líquida de vendas.

Fonte: PINTEC/IBGE, 2003, 2005 e 2007. Elaboração própria a partir dos dados obtidos na fonte.

Conforme se observa, ocorreu uma diminuição nos dispêndios em atividades inovativas de 2000 para 2003 e uma recuperação em 2005, sendo que o investimento em atividades inovativas como percentual da receita líquida de vendas da indústria apresentou o mesmo comportamento. Em 2000, as empresas inovadoras da indústria de equipamentos e materiais médico-hospitalares e odontológicos brasileira investiram 5,04\% da sua receita líquida de vendas em atividades inovativas. Em 2003, esse percentual reduziu-se para 3,07\% e, em 2005, sofreu uma recuperação situando-se em 5,29\%.

Deve-se considerar que o conceito de atividades inovativas utilizado pelo IBGE é bastante amplo incluindo, por exemplo, aquisição de máquinas e equipamentos, treinamento, aquisição de software, etc, bem como dispêndios em atividades internas de $P \& D$. Ao se considerar apenas este último indicador, constata-se que a relação de gastos internos sobre vendas foi de 1,77\% em 2000, 1,22\% 2003 e 2,26\% em 2005, muito aquém dos percentuais internacionais que, conforme visto anteriormente, se situam entre $5 \%$ e $12 \%$. 
A relação de gastos com atividades inovativas sobre vendas da indústria brasileira como um todo foi em 2000, 2003 e 2005, respectivamente, de 3,8\%, 2,5\% e 2,8\% (IBGE, 2003, 2005 e 2007). Ao se confrontar com os percentuais da indústria de equipamentos e materiais médico-hospitalares e odontológicos que foram, respectivamente, de 5,04\%, 3,07\% e 5,29\%, verifica-se que as empresas da indústria em questão apresentaram taxa de inovação bem acima da média nacional, estando incluídas, portanto, entre as atividades de alta intensidade tecnológica, o que claramente aponta para as características inerentes desta atividade. Entretanto, este dinamismo relativo situa-se muito aquém do verificado em nível mundial, não conferindo à indústria local competitividade internacional.

A não competitividade internacional das empresas da indústria pode ainda ser conferida por meio do comércio exterior da indústria deste subsistema. Ao se considerar a balança comercial como principal indicador da vulnerabilidade industrial, torna-se evidente a perda de competitividade da indústria, notadamente nos grupos mais dinâmicos e mais afetados pelos novos paradigmas tecnológicos: os aparelhos e equipamentos eletromédicos, odontológicos e laboratoriais, cujo processo produtivo vem sendo fortemente impactado pela microeletrônica. Além disso, a produção realizada por empresas situadas no território nacional ainda depende fortemente de insumos importados de maior conteúdo tecnológico, chegando a atingir 50\% em alguns segmentos.

Deve-se salientar que o déficit da indústria de equipamentos e materiais médico-hospitalares e odontológicos representa, atualmente, cerca de $20 \%$ do total do Complexo Econômico-Industrial da Saúde, atrás de fármacos (29\%) e de medicamentos (27\%). O gráfico 2 apresenta a evolução da balança comercial da indústria de 1996 a 2012.

Gráfico 02. Balança comercial de equipamentos e materiais médico-hospitalares e odontológicos, 1996-2012

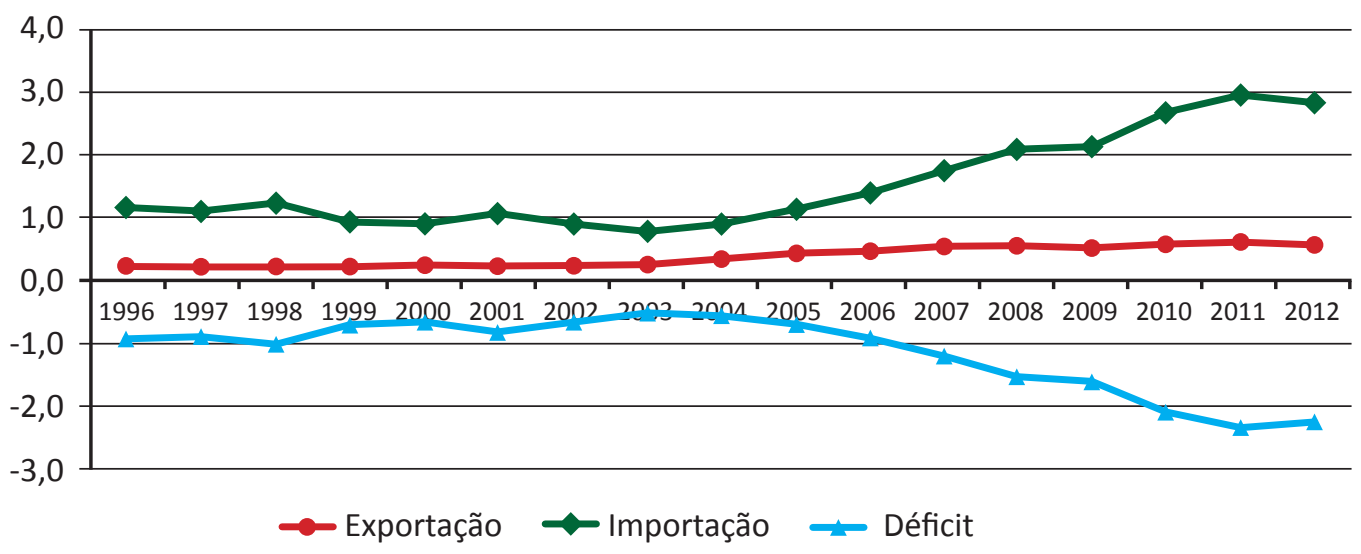

Fonte: elaborado por GIS/ENSP/FIOCRUZ, a partir de dados da Rede Alice / MDIC. Acesso em janeiro/2013. 
O déficit comercial saltou de um patamar de US\$200 milhões no final da década de 1980 para um valor em torno de US\$ 800 milhões em meados dos anos de 1990, sendo concentrado nos produtos eletrônicos (GADELHA, 2007). No período recente, o saldo comercial apresenta uma redução no triênio 2002/04 associado à desvalorização cambial, crise política, escassez de crédito, entre outros fatores, mas logo a seguir reverte esta tendência, situando-se próximo a US\$2,3 bilhão em 2012. 0 gráfico 3 detalha a composição do déficit comercial de 1996 a 2012, desagregado por produtos eletrônicos e não eletrônicos, material de consumo e órteses e próteses, a partir do qual se constata a forte predominância de produtos eletrônicos, ou seja, os de maior conteúdo tecnológico.

Gráfico 03. Equipamentos e materiais médico-hospitalares e odontológicos: composição do déficit comercial, 1996-2012

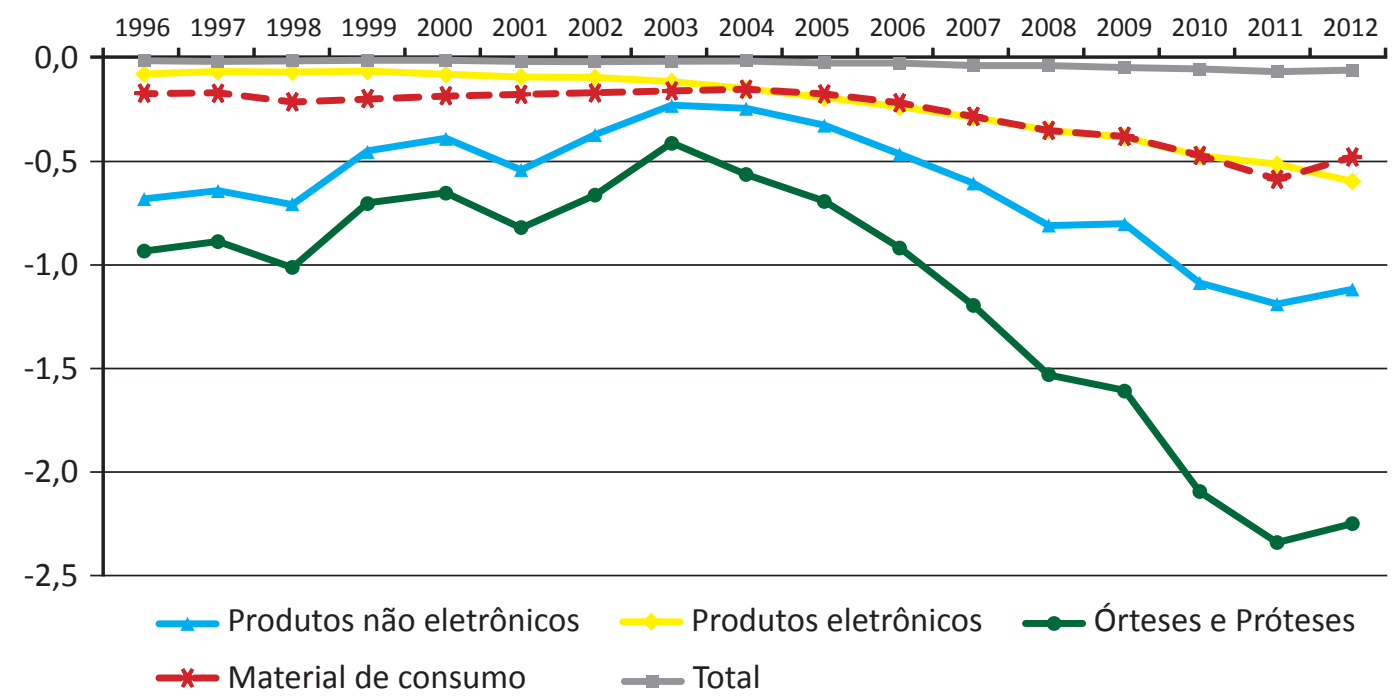

Fonte: elaborado por GIS/ENSP/FIOCRUZ, a partir de dados da Rede Alice/MDIC. Acesso em janeiro/2013.

O gráfico 4 apresenta a evolução do saldo comercial de 1996 a 2012, por principais parceiros comerciais. 
Gráfico 04. Equipamentos e materiais médico-hospitalares e odontológicos: principais parceiros comerciais, 1996-2012

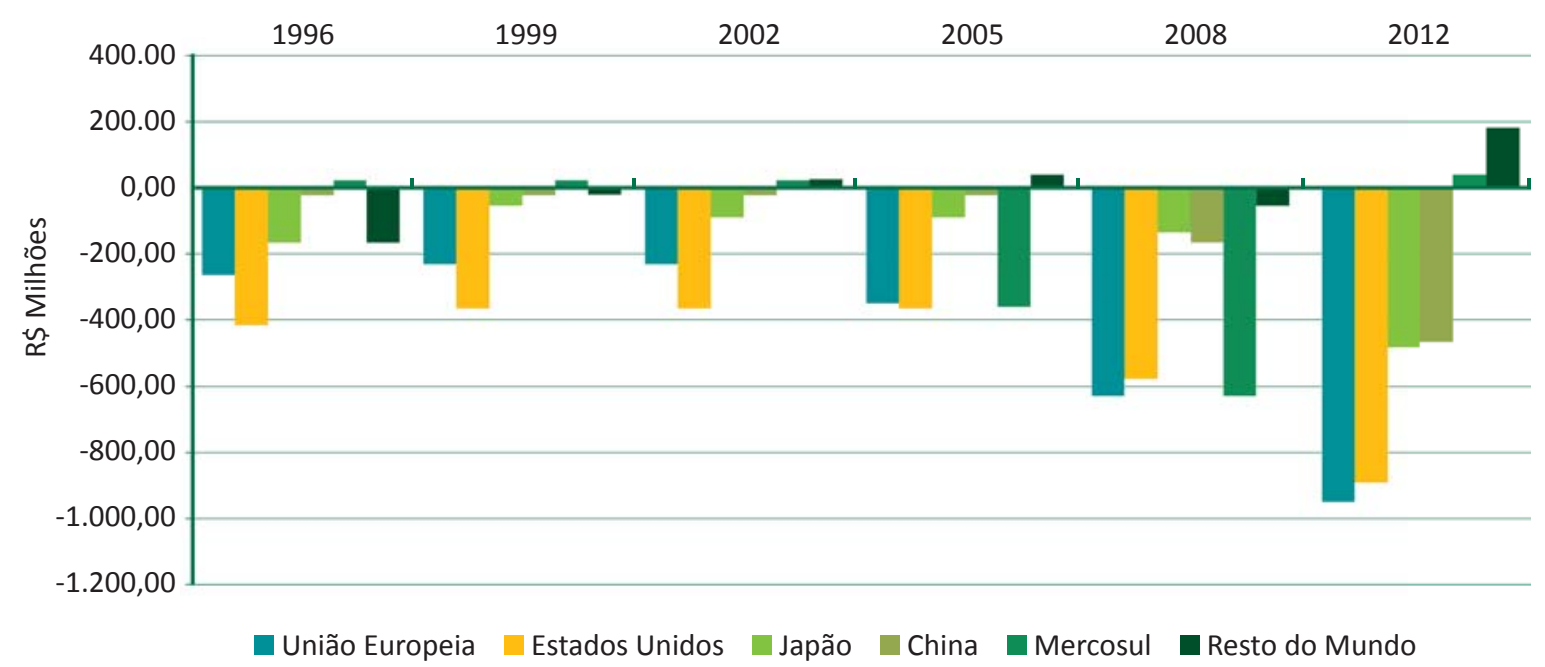

Fonte: elaborado por GIS-ENSP/FIOCRUZ, 2012, a partir dos dados da Rede Alice (SECEX/MDIC).

Verifica-se a forte dependência das importações em relação aos polos dinâmicos da indústria, nomeadamente EUA, União Europeia e Japão, ou seja, de produtos inovadores e de maior valor agregado e, crescentemente, da China. Pode-se afirmar que a origem das importações brasileiras é fortemente concentrada nos EUA, Alemanha e Japão; a participação destes três países nas importações totais da indústria deste subsistema em 2006 variava de 57,5\% em implantes até 70,3\% em equipamentos (LEÃO et al., 2008). Do lado das exportações, destaque-se a forte presença de países do Mercosul e do resto do mundo, de baixo dinamismo econômico, inclusive tecnológico, como destino de produtos brasileiros.

A indústria brasileira vem respondendo por cerca de 50\% do mercado interno total de equipamentos e materiais médico-hospitalares e odontológicos, sendo o restante suprido por importações. Contribuem para essa situação, que configura uma dependência externa, elementos tais como (ABDI, 2009b):

- A dependência do Brasil em importações de produtos de maior complexidade tecnológica.

- A dificuldade de acesso dos fabricantes locais no atendimento de demandas específicas; por exemplo, entidades filantrópicas e hospitais públicos ao se beneficiarem de tratamentos tributários diferenciados (isenção de impostos), optam pelo produto importado em detrimento do nacional. 
- A ausência de financiamento associado a vendas para produtos nacionais, como acontece com os bens importados, ainda que existam linhas de crédito para a comercialização de equipamentos.

Observa-se que no âmbito do Complexo Econômico-Industrial da Saúde este foi um dos poucos segmentos que apresentou respostas favoráveis no início da presente década, ampliando as exportações, ainda que a situação de dependência estrutural se tenha mantido em produtos de maior densidade tecnológica, impondo um obstáculo para a superação da vulnerabilidade internacional. Ou seja, há uma indústria importante de fabricação instalada no país que deu boas respostas frente à demanda local, mas no contexto da revolução microeletrônica, sua capacidade competitiva no futuro continua sendo ameaçada (GADELHA, 2007).

Deve-se ainda levar em consideração que embora a indústria brasileira deste subsistema ocupe a $17^{a}$ posição em termos do ranking mundial, esta é uma posição privilegiada quando se considera que é praticamente o único país na América do Sul e Central dotado de uma indústria relativamente completa de fabricação de equipamentos e materiais médico-hospitalares e odontológicos (VIANA et. al., 2011). Ademais, o atual dinamismo econômico do país em função de suas taxas de crescimento, associado à ampliação de seu sistema nacional de saúde, da extensão da cobertura das redes de assistência, da expansão dos gastos públicos em saúde, entre outros aspectos, apontam para perspectivas francamente positivas para esta indústria.

\section{3 | PERSPECTIVAS 2022/2030}

A evolução da indústria de equipamentos e materiais médico-hospitalares e odontológicos é fortemente impactada por fatores sociais, políticos, econômicos e tecnológicos. Estes elementos, ao se conjugarem de forma dinâmica, condicionarão o perfil e o desempenho competitivo da indústria entre 2022 e 2030.

\section{1 | Fatores Sociais}

Entre os aspectos sociais que influenciam a saúde de um modo geral e a indústria de equipamentos e materiais médico-hospitalares e odontológicos em particular, salientam-se a evolução demográfica e o perfil epidemiológico do Brasil.

A tabela 5 apresenta algumas tendências relativamente ao perfil demográfico do Brasil de 2000 a 2030. 
Tabela 05. Projeções demográficas no Brasil, 2000-2030

\begin{tabular}{c|c|c|c|c}
\hline Ano & $\begin{array}{c}\text { Esperança de vida } \\
\left(n^{\circ} \text { de anos }\right)\end{array}$ & $\begin{array}{c}\text { Taxas brutas de } \\
\text { natalidade }(\%)\end{array}$ & $\begin{array}{c}\mathbf{N}^{\circ} \text { de crianças de } \\
7 \text { a } 14 \text { anos }\end{array}$ & $\begin{array}{c}\text { Projeção da população } \\
\text { de 60 anos ou mais (\%) }\end{array}$ \\
\hline 2000 & 70,43 & 21,13 & 27.303 .080 & 8,12 \\
\hline 2005 & 71,88 & 18,45 & 26.545 .405 & 8,88 \\
\hline 2010 & 73,40 & 15,20 & 27.363 .936 & 9,98 \\
\hline 2015 & 74,79 & 13,19 & 26.522 .959 & 11,56 \\
\hline 2020 & 76,06 & 12,29 & 23.587 .526 & 13,67 \\
\hline 2025 & 77,20 & 11,57 & 21.195 .327 & 16,23 \\
\hline 2030 & 78,23 & 10,59 & 20.125 .700 & 18,70 \\
\hline
\end{tabular}

Fonte: IBGE, 2011.

Verifica-se que à medida que a esperança de vida do brasileiro aumenta, se reduzem as taxas de natalidade e o número de crianças de 7 a 14 anos, ao mesmo tempo em que cresce o número de indivíduos com mais de 60 anos. Neste sentido, - Brasil vivencia claramente um processo de envelhecimento populacional já experimentado pelos países desenvolvidos. Esta mudança na estrutura etária cria uma série de oportunidades e desafios para o sistema de saúde, gerando uma demanda futura por serviços de assistência, adequada alocação de recursos, provável elevação de custos e seus desdobramentos em termos de formulação de políticas públicas. Com o aumento da esperança de vida e da longevidade, ocorre uma mudança no padrão epidemiológico, com redução de doenças agudas e de origem infecciosa e aumento da incidência de doenças crônicas associadas ao envelhecimento e a consequente limitação das atividades do indivíduo.

A tabela 6 apresenta dados da carga de enfermidade para o Brasil em 1998 e 2013.

Tabela 06. Carga da enfermidade no Brasil por grandes grupos, 1998-2013

\begin{tabular}{l|c|c}
\multicolumn{1}{c|}{ Grupos } & Peso - 1998 & Peso - 2013 \\
\hline Doenças infecciosas e parasitárias* & $23,5 \%$ & $17,1 \%$ \\
\hline Doenças crônico-degenerativas & $66,3 \%$ & $74,1 \%$ \\
\hline Causas externas & $10,2 \%$ & $8,8 \%$ \\
\hline
\end{tabular}

* Inclui causas maternas, perinatais e nutricionais.

Fonte: Gadelha et al., 2012. 
Verifica-se a tendência de crescimento das doenças crônico-degenerativas em detrimento das doenças infecciosas e parasitárias e de causa externa. No âmbito das principais doenças em 2013, salienta-se a título de exemplo e por ordem decrescente de importância o diabetes mellitus, doença isquêmica do coração, doenças cerebrovasculares, transtornos depressivos recorrentes e doenças pulmonares crônicas (GADELHA et al., 2012).

Complementando esta perspectiva, Borges (2008), em um estudo para a região metropolitana do Rio de Janeiro entre 2000 e 2050, projetou as tendências futuras da deficiência na população em idades avançadas. A tabela 7 apresenta uma comparação entre os riscos de desenvolver uma deficiência em idosos por sexo em função das principais doenças e agravos responsáveis pela carga de morbidade em 2000 e 2050, em três cenários, otimista, constante e pessimista.

Em que pesem as diferenças relativas entre homens e mulheres, nos três cenários as doenças crônico-degenerativas como câncer, doenças neuropsiquiátricas e cardiovasculares serão responsáveis pela maior parte das deficiências da população idosa em 2050, confirmando as perspectivas de curto prazo.

Conforme Borges (2008) destaca, existe uma convergência entre as principais doenças e agravos que compõem a projeção do indicador de anos vividos com incapacidade e as doenças que respondem pela maior parte das internações e custos do SUS, estimando-se um aumento significativo em termos de demanda por assistência de saúde pela população em idade avançada, assim como uma elevação dos custos associados ao tratamento dessas doenças. Ademais, conforme salienta Schramm et al. (2004), a importância crescente das doenças crônico-degenerativas como problema de saúde pública requer a reestruturação do sistema nos níveis básico e hospitalar no sentido de promover a medicina preventiva, o diagnóstico e o tratamento precoce das incapacidades geradas por estes agravos.

Modificações no perfil de saúde da população associadas ao processo de envelhecimento da população brasileira requererão mudanças no padrão de utilização dos serviços de saúde com consequente aumento de custos, considerando a necessidade de incorporação tecnológica para o tratamento das mesmas, ao mesmo tempo em que se constituem elementos fundamentais para a formulação de políticas públicas e de estratégias empresariais de longo prazo, particularmente, da indústria de equipamentos e materiais médico-hospitalares e de odontológicos. 
Tabela 07. Risco de desenvolver deficiência na população de 60 anos ou mais por sexo e cenários de projeção segundo as principais causas de deficiência na região metropolitana do Rio de Janeiro, 2000-2050

\begin{tabular}{|c|c|c|c|c|c|c|}
\hline \multirow{3}{*}{ Causas Específicas } & \multicolumn{6}{|c|}{ Risco de Desenvolver Deficiência na População de 60 anos ou mais } \\
\hline & \multicolumn{3}{|c|}{2000} & \multicolumn{3}{|c|}{2050} \\
\hline & Otimista & Constante & Pessimista & Otimista & Constante & Pessimista \\
\hline \multicolumn{7}{|c|}{ Homens } \\
\hline Câncer & 11,40 & 11,82 & 14,52 & 22,07 & 23,63 & 29,04 \\
\hline Causas externas não intencionais & 0,37 & 0,40 & 0,49 & 6,73 & 7,21 & 8,86 \\
\hline Desordens dos órgãos do sentido & 1,91 & 2,05 & 2,52 & 2,10 & 2,25 & 2,77 \\
\hline Doenças cardiovasculares & 4,04 & 5,40 & 6,63 & 8,42 & 9,02 & 11,08 \\
\hline Doenças do aparelho digestivo & 0,82 & 0,88 & 1,08 & 0,90 & 0,97 & 1,19 \\
\hline Doenças neuropsiquiátricas & 8,42 & 9,01 & 11,07 & 11,43 & 12,24 & 15,04 \\
\hline Infecciosas e parasitárias & 3,01 & 3,23 & 3,96 & 1,94 & 2,07 & 2,55 \\
\hline \multicolumn{7}{|c|}{ Mulheres } \\
\hline Câncer & 15,69 & 16,80 & 20,65 & 31,38 & 33,61 & 41,29 \\
\hline Causas externas não intencionais & 1,65 & 1,77 & 2,18 & 4,72 & 5,06 & 6,22 \\
\hline Desordens dos órgãos do sentido & 1,25 & 1,34 & 1,64 & 3,60 & 3,85 & 4,73 \\
\hline Doenças cardiovasculares & 2,59 & 2,77 & 3,40 & 2,85 & 3,05 & 3,75 \\
\hline Doenças do aparelho digestivo & 7,73 & 8,27 & 10,17 & 12,91 & 13,83 & 16,99 \\
\hline Doenças neuropsiquiátricas & 6,05 & 6,48 & 7,96 & 15,83 & 16,95 & 20,83 \\
\hline Infecciosas e parasitárias & 6,49 & 6,94 & 8,53 & 4,17 & 4,47 & 5,49 \\
\hline
\end{tabular}

Fonte: Borges, 2008.

\section{2 | Fatores Políticos}

Recentemente, o país assistiu à retomada de uma estratégia de desenvolvimento com a formulação de política industrial, entendida como necessária para enfrentar os desafios da globalização e da inserção competitiva brasileira. O marco desta nova perspectiva foi o lançamento, em março de 2004 da nova Política Industrial, Tecnológica e de Comércio Exterior (BRASIL, 2003), envolvendo diversas instâncias decisórias no âmbito federal, refletindo que se tratava de uma orientação de governo e não uma política insulada e específica de um ministério ou agência. A PITCE propõe que a política industrial privilegie um conjunto de ações que são essenciais para toda estrutura produtiva, em uma perspectiva de inserção competitiva da indústria, e que possuem relevância para indústria de equipamentos e materiais médico-hospitalares 
e odontológicos, a saber: inovação e desenvolvimento tecnológico, inserção externa, modernização industrial e capacidade e escala produtiva (2003).

Lançada em maio de 2008, a Política de Desenvolvimento Produtivo (PDP) tem como objetivo central sustentar o ciclo de expansão atual dos setores da economia brasileira. Desta forma, está estruturada em torno de programas com metas específicas que possuem macrometas em comum: ampliação do investimento fixo, elevação do gasto privado em Pesquisa e Desenvolvimento, ampliação das exportações e dinamização das pequenas e médias empresas. Entre os programas mobilizadores em áreas estratégicas, insere-se o Complexo Industrial da Saúde ${ }^{6}$ pelo seu potencial competitivo que necessita ser desenvolvido por meio do aumento na capacitação e na competitividade dos atores envolvidos (BRASIL, 2008a).

Paralelamente à PDP foi criado no âmbito do Ministério da Saúde o Grupo Executivo do Complexo Industrial da Saúde - GECIS, um fórum permanente envolvendo vários ministérios e instituições estratégicas para o CEIS, objetivando uma articulação entre atores do campo da política industrial e de CT\&I e da Saúde e a sociedade civil, para a proposição de ações consideradas relevantes e estratégicas para o desenvolvimento do marco regulatório de implantação da estratégia de desenvolvimento para a área da saúde (BRASIL, 2008b).

Em uma ação sistêmica e de articulação com programas em desenvolvimento, foi lançado em 2008 o Programa Mais Saúde: direito de todos, também designado de PAC Saúde, inserido no contexto do Programa de Aceleração do Crescimento (PAC). No total, estão previstas 73 medidas e 165 metas, com um orçamento de $\mathrm{R} \$ 89,4$ bilhões, distribuídas em sete eixos. Um desses eixos diz respeito aos setores que conformam o Complexo Econômico-Industrial da Saúde e as duas diretrizes focalizam o fortalecimento do Complexo por meio de transformações da estrutura produtiva e de inovação e o aumento da competitividade das empresas e dos produtores públicos e privados das indústrias da saúde de forma que estes possam enfrentar a concorrência internacional e oferecer produtos e insumos compatíveis com o padrão tecnológico e de consumo que se configura no campo da saúde.

No caso da indústria de equipamentos e materiais médico-hospitalares e odontológicos uma das metas é substituir 25\% da demanda de equipamentos e materiais do SUS por produção nacional até 2011, por meio de medidas de fomento à capacidade produtiva e de inovação das empresas nacionais, em parceria com o BNDES e a FINEP (BRASIL, 2007).

Especificamente para o setor estratégico de fármacos e medicamentos, o BNDES dispunha de linha especial, o Programa de Apoio ao Desenvolvimento da

6 Gadelha et al. (2009) adotam o termo Complexo Econômico-Industrial da Saúde (CEIS) ao invés de Complexo Industrial da Saúde (CIS) para demarcar a visão de que existe um verdadeiro Sistema Produtivo da Saúde que mobiliza parte substantiva da economia nacional. 
Cadeia Produtiva Farmacêutica — Profarma, com vigência até dezembro de 2007. Recentemente, o BNDES anunciou sua renovação, tendo sido renomeado para Programa de Apoio ao Desenvolvimento do Complexo Industrial da Saúde, coloquialmente designado de Profarma 2, e estendido aos demais segmentos do Complexo, incluindo a indústria de equipamentos e materiais médico-hospitalares e odontológicos. O objetivo do programa é elevar a competitividade do Complexo Econômico-Industrial da Saúde por meio da disseminação da atividade inovadora, aumento da produção e consequente inserção internacional das empresas nacionais, dispondo para isso, de R $\$$ 3 bilhões para o período entre 2008 e 2012 (BNDES, 2010).

Para aumentar a competitividade da indústria nacional, sob o lema "Inovar para Competir, Competir para Crescer", já no governo Dilma foi instituído em 2011 o Programa Brasil Maior. O Programa compreende uma nova política industrial, tecnológica, de serviços e de comércio exterior visando o estímulo à inovação e à produção nacional para alavancar a competitividade da indústria. No campo social representa um esforço para a integração de geração de emprego e renda em benefício do povo brasileiro. Entre as medidas previstas, saliente-se a Lei de Compras Governamentais, que estipula uma margem de preferência de até $25 \%$ nos processos de licitação para produtos manufaturados e serviços nacionais que atendam às normas técnicas brasileiras. Essas margens serão definidas levando em consideração a geração de emprego e renda, o desenvolvimento e a inovação tecnológica realizados no país. Além disso, o dispositivo será usado também para fortalecer pequenos e médios negócios em algumas áreas, dentre elas, a saúde (BRASIL, 2011).

No âmbito das iniciativas governamentais saliente-se ainda a Lei da Inovação, regulamentada em 2005, a qual pretende viabilizar mecanismos de desenvolvimento tecnológico de forma a facilitar a relação entre empresas e instituições de pesquisa (BRASIL, 2005). Destaque-se também, o Fundo Setorial de Saúde cujo objetivo é a capacitação tecnológica nas áreas de interesse do SUS, o estímulo ao aumento dos investimentos privados em $\mathrm{P} \& \mathrm{D}$, a atualização tecnológica da indústria brasileira de equipamentos e materiais médico-hospitalares e odontológicos, e a difusão de novas tecnologias que ampliem o acesso da população aos bens e serviços na área de saúde (FINEP, 2010). Dentre as ações voltadas para a modernização industrial, notese o Programa Brasileiro de Avaliação de Conformidade e Atividades de Metrologia o qual contempla diversos produtos do segmento em questão (INMETRO, 2010).

Estas iniciativas, cujos efeitos plenos se farão sentir no futuro próximo, a par do crescimento econômico do país nos últimos anos e suas perspectivas futuras, configuram um contexto político-institucional auspicioso para a indústria de equipamentos e materiais médico-hospitalares e odontológicos.

Um papel ativo do Estado na definição e implementação de políticas públicas de reforço e ampliação das vantagens competitivas da indústria nacional é 
condição essencial ao desempenho futuro da mesma. De acordo com a ABIMO (2010), o poder público representava $21,5 \%$ das compras da indústria em 2009; todavia, como ressaltam Pieroni et al. (2010), parte significativa das compras de entidades privadas é reembolsada pelo sistema público de saúde o que, na prática, aponta para uma demanda próxima de 50\% dos produtos vendidos pela indústria. Assim, o Estado, pelo seu papel de grande consumidor de bens e serviços da indústria, pode direcionar o desenvolvimento da mesma, por meio do estabelecimento de compras preferenciais.

Nesta direção, o Ministério da Saúde, por meio da Portaria nº 978 de maio de 2008 identificou um conjunto de equipamentos e materiais de consumo prioritários no âmbito do SUS como itens que deveriam receber apoio em termos do adensamento tecnológico envolvido (BRASIL, 2008c). Em maio de 2010, a Portaria $n^{\circ} .1 .284$ do mesmo ministério atualizou a anterior. De acordo com a nova Portaria, os critérios utilizados na seleção destes produtos foram: aderência aos programas desenvolvidos pelo Ministério da Saúde; nível de produção nacional; número de fabricantes no país; destacado índice de queixas técnicas ou eventos adversos notificados à Anvisa associados a produtos nacionais; e demanda técnica para certificação de produtos (BRASIL, 2010).

Ainda de acordo com a mesma Portaria são mantidos como equipamentos e materiais prioritários os produtos constantes da Portaria $n^{\circ}$. 978, que permanecem com níveis inexpressivos de produção nacional ou com baixo número de fabricantes no país (BRASIL, 2008).

A identificação de equipamentos e materiais prioritários do ponto de vista nacional está em perfeita sintonia com o previsto no Programa Mais Saúde que, entre as suas metas, estabeleceu a substituição de $25 \%$ da demanda de equipamentos e materiais adquiridos pelo SUS por produção nacional, até 2011 (BRASIL, 2007).

Em um processo de alterações no perfil da demanda de saúde no país associado ao envelhecimento da população, as necessidades de expansão e melhoria do Sistema Público de Saúde devem se ampliar. Todavia, as perspectivas de financiamento do Estado brasileiro não se apresentam promissoras. Em 2008, o Brasil apresentava uma baixa participação dos gastos públicos em saúde com $44 \%$ dos gastos totais, comparativamente tanto aos países da OCDE cujo dispêndio médio do sistema público representava mais de 70\%, quanto aos países do Mercosul cuja média era de 52,7\% (WHO, 2011). As características do Sistema Público de Saúde brasileiro em que constitucionalmente a saúde pública é de caráter universal, integral e equânime, a par da perspectiva crescente de aumento da demanda, apontam claramente para a necessidade de ampliação dos gastos públicos em saúde. 


\subsection{Fatores Econômicos}

O crescimento do mercado brasileiro de equipamentos médicohospitalares associado à ampliação do sistema de saúde suplementar, taxa de câmbio, ampliação do crédito para aquisição de equipamentos, o lançamento do PAC Saúde, entre outros aspectos, vem atraindo a atenção das grandes multinacionais da indústria. A Siemens foi a primeira a instalar uma fábrica de raios X no Brasil; a GE está implantando sua fábrica em Contagem, Minas Gerais, com início de operação previsto para meados de 2009; a Toshiba ainda avalia o mercado (FRANÇA, 2008). Os investimentos externos na indústria apresentaram um crescimento de $435 \%$ de 2003 a 2006, tendo a indústria de equipamentos propriamente dita respondido por mais de 80\% destes recursos em detrimento da indústria de materiais. Países Baixos, Suíça, Espanha, Suécia e EUA responderam por 87\% destes recursos (LEÃO et al., 2008).

A nova planta da GE Healthcare para a fabricação de aparelhos de raio X e mamografia foi inaugurada em julho de 2010. Com investimentos de US\$ 50 milhões para os próximos 10 anos, a empresa planeja expandir sua capacidade produtiva já para 2011, para sistemas de monitoramento, ressonância magnética, tomografia computadorizada e PET/CT usado no diagnóstico do câncer (POLONI, 2010).

A Alert Life Sciences Computing S.A., empresa portuguesa que investiu mais de US\$ 1 milhão no Brasil, oferece um sofisticado protocolo para informatização de sistemas de atendimento de emergência, o Protocolo de Manchester usado na Inglaterra. A empresa fechou um acordo com o governo de Minas Gerais no valor de R $\$$ 48 milhões para informatizar o atendimento de 19 Pronto-Socorros no estado mineiro até 2010. Pelo sistema, o paciente passa por uma triagem inicial e a fila é organizada eletronicamente através da avaliação do risco e não mais pela ordem de chegada, o que gera um atendimento mais rápido e eficiente, mais seguro e reduz custos. A empresa, inclusive, fechou contrato para informatização da rede das Santas Casas (FRANÇA, 2008).

Além de investimentos externos, a indústria vem sendo objeto de aquisições por parte das grandes multinacionais. Em 2006, a 3M adquiriu a divisão de segurança da POMP Produtos Hospitalares e Segurança do Trabalho Ltda, fornecedora de produtos para a proteção individual do trabalhador, o que reforça a posição da adquirente no mercado hospitalar nacional (GELLERMANN \& LEONARDO, 2006). Em 2007, a Philips adquiriu a VMI, empresa que detinha uma forte presença no mercado de raio $\mathrm{X}$ e nos segmentos de cateterismos, mamografia e ultra-som (CECOTOSTI, 2007) e, em 2008, adquiriu a Dixtal, o maior fabricante brasileiro de monitores de leitos de hospital e aparelhos médicos para respiração e anestesia (SOUZA, 2008). Com a aquisição da VMI a empresa planeja a inauguração da produção de equipamentos de ressonância magnética no Brasil. Em 2010, a empresa adquiriu a Tecso, empresa focada em Radiology Information System, visando fortalecer sua posição competitiva na 
indústria (MARTINS, A. 2010). Também em 2010, a Philips adquiriu a Wheb Sistemas, empresa especializada em sistema de gestão hospitalar. Estas aquisições sinalizam o seu novo modelo de negócios no país, que deixa de ser somente na comercialização de equipamentos e passa a ser na oferta de projetos integrados (SOUZA, 2010).

Outra tendência que vem promovendo impactos nesta indústria é a crescente incorporação das tecnologias de informação e comunicação. Neste sentido, os grandes hospitais e instituições médicas em busca de redução de custos, rapidez no atendimento e aumento da qualidade do diagnóstico, investem em programas e sistemas de informação.

No início de 2008, o Hospital das Clínicas adquiriu da Philips um sistema para armazenamento e distribuição digital de imagens médicas que, além dos equipamentos de raio X digital e da plataforma de tecnologia da informação, envolveu o fornecimento de serviços de consultoria de gestão, diagnóstico das necessidades, melhoria da produtividade e planejamento estratégico. O sistema que deverá ser estendido a todas as unidades do Hospital das Clínicas, representa uma economia de cerca de R\$ 1,5 milhão por ano com a eliminação de custos com compras de filmes e revelações, além de um ganho de 30\% em produtividade (NASCIMENTO, 2008).

Em outubro de 2008, com tecnologia da Agfa HealthCare do Brasil, o Hospital Sírio Libanês inaugurou o Centro de Diagnóstico por Imagem (CDI) e sala de Cirurgia Inteligente amparado por sistema PACS (Picture Archiving and Communication System). Tal sistema permite digitalizar, armazenar e consultar em rede todas as imagens dos exames dos pacientes em modalidades médicas como ressonância magnética, tomografia, ultrassonografia, entre outros (MALDONADO, 2007a).

Estes elementos em conjunto — contexto político favorável, investimentos externos diretos, aquisições e impacto das TIC no sistema produtivo da saúde deverão promover impactos significativos no modus operandi da indústria nacional. O crescente interesse das multinacionais pelo mercado brasileiro, seja sob a forma de investimentos externos diretos, seja via aquisições de empresas locais, deverá se intensificar no futuro próximo. A busca por vantagens competitivas específicas de alguns players internacionais no mercado brasileiro, a exemplo da Siemens, GE e Philips - melhor adaptação do produto à demanda local, melhor qualidade, custos mais baixos prestados aos clientes, capacidade de atendimento às exigências dos consumidores, entre outros aspectos — deverá induzir, no âmbito da mútua interdependência oligopolista, movimentos similares de outros competidores mundiais.

Outro aspecto a ser salientado diz respeito ao posicionamento competitivo das empresas. A transação de Philips com o Hospital das Clínicas, por exemplo, representou a adoção de um novo modelo de negócios na área. Além dos serviços de consultoria, o cliente não precisou comprar o sistema, uma vez que fará o pagamento por transmissão. No caso do Hospital das Clínicas, o valor por cada transmissão será 
ao redor de $\mathrm{R} \$ 1$, ao invés de um investimento mínimo de implantação do sistema de mais de R\$ 8 milhões (NASCIMENTO, 2008). Esta transação representou efetivamente a oferta de soluções integradas, isto é, produtos associados a serviços, reforçada pela marca, reputação e outros elementos intangíveis que esta multinacional dispõe.

A crescente presença de multinacionais no mercado brasileiro e o enfoque das estratégias de comercialização das grandes empresas, seguramente, promoverão uma maior concentração, acirramento da concorrência e aumento das barreiras à entrada nos segmentos nos quais elas se instalarem, impedindo ou mesmo excluindo as empresas de menor porte que dispõem de menos recursos.

Outro elemento diz respeito aos impactos na balança comercial. Deve-se ressaltar que a presença física de empresas globais produzindo no país equipamentos similares nacionais, não terá, de imediato, maiores impactos na balança comercial. De acordo com a legislação brasileira, a isenção de impostos beneficia somente o equipamento que não tiver similar nacional, sendo este definido como o produto fabricado no país capaz de substituir os importados. Além disso, a existência de similares nacionais impede as importações de produtos remanufaturados para aquela modalidade. Na medida em que já existem no país fabricantes de aparelhos de raio X analógico, espera-se que com a incursão da Philips nesta área, os maiores beneficiários sejam os usuários finais.

A situação será muito diferente, porém, se estas empresas globais decidirem investir em plantas locais para a produção, por exemplo, de aparelhos de ressonância magnética ou tomografia computadorizada, conforme prevê a Philips. Neste caso, a categoria de produto remanufaturado será extinta e o equipamento importado sofrerá tributação, beneficiando o fabricante local e promovendo impactos na balança comercial (MITO, 2008).

Em um cenário de médio prazo para o Brasil, avalia-se que as mudanças, sobretudo as de cunho tecnológico, se processem de modo incremental. A entrada de subsidiárias de grandes multinacionais na fabricação de produtos que não têm correspondente nacional significará um processo de substituição de importações e, concomitantemente, um adensamento do perfil tecnológico e industrial da indústria nacional, e não uma aproximação efetiva da fronteira tecnológica em termos mundiais.

A definição de prioridades do ponto de vista brasileiro que promova o reforço das vantagens competitivas das empresas nacionais e as conduza para patamares de maior densidade tecnológica em termos dos produtos oferecidos, tornase crucial. Conforme visto anteriormente, a parcela dinâmica da indústria, em termos das taxas de crescimento e da inovação, adesão às práticas regulatórias, atendimento da demanda interna, exportações sustentáveis e maior conteúdo tecnológico relativo, se situa nos segmentos de equipamentos médico-hospitalares, próteses e implantes 
e odontológico. Estes segmentos representam os nichos de mercado para um pleno desenvolvimento competitivo da indústria nacional. Impõe-se, entretanto, a definição e implementação de políticas públicas de promoção de estratégias de especialização em conjunção com o uso do poder de compra do Estado.

\section{4 | Fatores Tecnológicos}

Em termos tecnológicos, os principais elementos no campo da saúde que terão influência no comportamento da indústria de equipamentos e materiais médicohospitalares e odontológicos no Brasil em longo prazo referem-se a pressões por reduções de custos, medicina preventiva, telemedicina, atenção domiciliar e crescente incorporação de novas tecnologias (EXPORTMED BRAZIL, 2004; ABDI, 2009b).

O envelhecimento da população e a ampliação dos serviços de saúde no sentido da universalização e integralização são dois elementos que, conjugados, deverão exercer forte pressão sobre os gastos públicos e privados com a saúde. Neste cenário, a indústria de equipamentos deverá sofrer fortes e crescentes pressões no sentido de que seus desenvolvimentos tecnológicos levem em conta não somente o aumento da qualidade dos padrões de tratamento e diagnóstico no sentido de serem mais efetivos, mais rápidos, mais seguros e menos invasivos para uma grande variedade de doenças, mas também no sentido de sua capacidade de reduzirem o custo dos tratamentos (ETTLINGER, 2005).

Em um quadro geral de ampliação de serviços de saúde e seus custos, dever-se-á dar importância crescente à medicina preventiva, isto é, ao diagnóstico precoce. Os serviços de saúde em geral, e os equipamentos neles utilizados deverão responder ao caráter cada vez mais preventivo dos atendimentos, reduzindo tempos de internação e de recuperação, custos e, concomitantemente, reduzindo a taxa de prestação de serviços.

Telemedicina compreende a oferta de serviços ligados aos cuidados com a saúde, nos casos em que a distância é um fator crítico; tais serviços são prestados por profissionais da área da saúde, usando tecnologias de informação e de comunicação para o intercâmbio de informações válidas para diagnósticos, prevenção e tratamento de doenças e a contínua educação de prestadores de serviços em saúde, assim como para fins de pesquisas e avaliações (RNP, 2008).

A maior parte das especialidades médicas já utiliza tecnologia da informação e comunicação para o desenvolvimento da prática médica à distância. O contínuo desenvolvimento da tecnologia de telecomunicações vem abrindo novas possibilidades para a prestação de serviços em regiões distantes. Dentre os usos de telemedicina mais conhecidos estão a videoconferência médica, os trabalhos colaborativos e o estudo de casos na área de pesquisa; a educação a distância, a 
educação continuada, a especialização, o aperfeiçoamento e a atualização na área de capacitação profissional.

No Brasil, as ações em telemedicina vêm sendo realizadas desde a década de 1990, porém de forma tímida. Um país com dimensões continentais, no entanto, tem muito a ganhar com a formação e a consolidação de redes colaborativas integradas de assistência médica à distância. Benefícios como a redução de custos com transportes e comunicações e a possibilidade de levar a medicina especializada a regiões remotas do país mediante a consulta on-line e o telediagnóstico por imagem na área de atendimento são apontadas como as principais vantagens da telemedicina (RNP, 2008). Neste sentido, equipamentos médicos de custo de aquisição e de manutenção alto, poderão concentrarse em locais estratégicos e conectados em rede a uma série de usuários. Abre-se assim, uma área de grande potencial que é o campo de equipamentos de baixo custo, com o aproveitamento, por exemplo, das potencialidades dos microcomputadores.

A atenção domiciliar, viabilizada pelas tecnologias da informação e comunicação, é uma modalidade de cuidado à saúde na qual o paciente pode tratar da sua doença em casa junto da família, possibilitando uma recuperação mais rápida. A atenção domiciliar constitui uma estratégia de desospitalização e é uma das áreas na qual se prevê um forte crescimento. Estima-se que os equipamentos médicos utilizados na atenção domiciliar representavam um mercado mundial de US\$ 41 bilhões em 2009; as projeções apontam para um crescimento anual deste segmento de 7\% a.a., atingindo um patamar de US\$ 67 bilhões em 2016 (PARTNERING NEWS, 2011).

Neste tipo de procedimento, o paciente poderá fazer o próprio exame em casa, enviá-lo ao médico pela linha telefônica ou pela internet e este poderá orientar o paciente pelos mesmos meios. Mesmo em postos de saúde, onde em geral não há um especialista atendendo, o próprio clínico fará o exame no paciente, transmitirá o resultado a um especialista dentro de um hospital, que fará o diagnóstico, orientando o médico clínico no posto de saúde ou no pronto-socorro. Acredita-se que esse tipo de procedimento nos casos de emergência, em um país de dimensões continentais como é o caso do Brasil, poderá salvar muitas vidas. Outra área que se prevê grande impacto é no tratamento de pacientes crônicos; se desospitalizados, estes pacientes promoverão impactos positivos em termos de custos hospitalares, ao mesmo tempo em que abrirão leitos para pacientes eletivos (SANTANA, 2008).

Esta modalidade de tratamento à saúde — atendimento médico domiciliar - abre a possibilidade da coleta laboratorial para análises clínicas na residência do paciente, do envio de exames e acompanhamento do paciente à distância, entre outros aspectos. Esta modalidade deverá crescer em razão do envelhecimento da população, da necessidade de humanização do atendimento, bem como da economia de recursos gerada e da redução do tempo de internação (REHEM e TRAD, 2005). Essa mudança forçará as empresas a buscarem alternativas que resultem em equipamentos 
dotados de portabilidade, conectividade e segurança para que possam ser operados por não especialistas. Monitores de glicose, dispositivos para aplicação de insulina, nebulizadores e concentradores de oxigênio são exemplos de equipamentos que se enquadram nesta categoria (PARTNERING NEWS, 2011).

Especificamente no campo das TIC aplicadas à saúde humana e que representarão oportunidades para a indústria de equipamentos e materiais médicohospitalares e odontológicos, a tabela 8 apresenta as principais tendências tecnológicas para o período 2016-2025, ressaltando-se a informática em saúde, a biomédica e a engenharia biomédica.

A par das tecnologias da informação e comunicação, que no presente já estão sendo incorporadas nos equipamentos médico-hospitalares conforme exemplos citados e cujas tendências apontam para uma intensificação deste processo que viabilizarão a telemedicina e a atenção domiciliar, destaque-se, entre outras, a nanotecnologia e os novos materiais como as principais perspectivas para os próximos anos.

A nanotecnologia permite trabalhar em escala quântica/atômica. Ao variar a estrutura e a composição de materiais comuns, os cientistas podem mudar dramaticamente suas propriedades físicas, químicas e biológicas. As nanopartículas podem viajar livremente pela corrente sanguínea para atacar um câncer específico, podem ser colocadas em um colírio para tratar de um glaucoma e podem produzir microdispositivos médicos capazes de tornar possíveis cirurgias atômicas (MALDONADO, 2007b). Prevê-se que medicamentos nanotecnológicos atuarão como minúsculos dispositivos guiados para a liberação progressiva do fármaco a alvos específicos e com diminuição de efeitos indesejados causados pelos fármacos (POLLETO et al, 2008).

Em termos de tecnologias de monitoração, por exemplo, o desenvolvimento de moléculas com capacidade de se reconhecerem mutuamente pode viabilizar novos sensores químicos e biossensores para uso em equipamentos como capinógrafos (monitoramento do dióxido de carbono), oximetria (medição do nível de oxigênio), detectores de nível de glicose e pressão sanguínea. Pelo tamanho e dimensão destes sensores será possível colocá-los dentro do paciente de forma que transmitam dados coletados do mesmo por meio de pequenos dispositivos de comunicação eletrônica. A grande vantagem destas tecnologias será a de disponibilizar a monitoração em tempo real de parâmetros biológicos e bioquímicos do paciente (ABDI, 2009b).

Na área de imagens, por exemplo, prevê-se o desenvolvimento de câmeras de nanotecnologia, compostas de diversas unidades semelhantes aos olhos compostos dos insetos, a serem utilizadas dentro do corpo humano. Cada unidade fornecerá parte da imagem, dotada de bioluminescência. O tamanho reduzido permite que as unidades vejam qualquer área do corpo humano sem necessidade de operação. Esse é um exemplo do desenvolvimento futuro da tecnologia microscópica para novos usos (MALDONADO, 2007). 
Tabela 08. Principais tendências tecnológicas das TIC aplicadas à saúde humana, 2016-2025

\begin{tabular}{|c|c|}
\hline Tecnologia & Descrição \\
\hline \multirow{6}{*}{$\begin{array}{l}\text { Informática } \\
\text { em Saúde }\end{array}$} & $\begin{array}{l}\text { Compreende o armazenamento, a recuperação e o uso da informação, dados e conhecimento biomédicos } \\
\text { para a resolução de problemas e tomada de decisão. Envolve as seguintes áreas de atuação: }\end{array}$ \\
\hline & $\begin{array}{l}\text { Sistemas de informação em Saúde: mecanismos de coleta, processamento, análise e transmissão de } \\
\text { informações necessárias para se planejar, organizar, operar e avaliar os serviços de saúde }\end{array}$ \\
\hline & $\begin{array}{l}\text { Prontuário eletrônico do paciente: sistemas que interliguem todas as informações do paciente, inclusive } \\
\text { dados interdepartamentais e interinstitucionais, permitindo que os fluxos de informação se traduzam } \\
\text { na interação entre distintas áreas clínicas e não clínicas e as diversas partes envolvidas - pacientes } \\
\text { profissionais de saúde, instituições prestadoras de serviços assistenciais públicas ou privadas, órgãos de } \\
\text { saúde coletiva, instâncias de governo e organizações nãogovernamentais. }\end{array}$ \\
\hline & $\begin{array}{l}\text { Sistemas de apoio à decisão: sistemas de consulta que usam uma estatística populacional e conhecimento } \\
\text { especializado para oferecer informações aos médicos; auxiliam na consulta e tratamento através da análise } \\
\text { da informação específica de um paciente comparando-a ao conhecimento especializado do banco de } \\
\text { dados, devendo melhorar a qualidade do atendimento e diminuição de custos do atendimento. }\end{array}$ \\
\hline & $\begin{array}{l}\text { Processamento de sinais biológicos: processamento de sinais biológicos/biomédicos com o objetivo } \\
\text { de extrair informações significativas a partir de sinais biomédicos através de tecnologia digital (por } \\
\text { software ou programas especializados de computador); apresenta redução de custos e maior flexibilidade } \\
\text { comparativamente aos sistemas analógicos }\end{array}$ \\
\hline & $\begin{array}{l}\text { Processamento de imagens médicas: o processamento de imagens médicas leva em consideração os } \\
\text { avanços nos processos de captação de imagens e formas de interpretação de conteúdos digitais, cuja } \\
\text { interpretação das mesmas é baseado em técnicas de Inteligência Artificial; a imagem é realçada para a } \\
\text { visualização humana ou para posterior análise pelo computador e modelos matemáticos são utilizados } \\
\text { para ajudar na execução de análise de imagens automatizadas, sendo que estes processos envolvem a } \\
\text { fusão de imagens aliados à gestão de imagens e informações agregadas }\end{array}$ \\
\hline Bioinformática & $\begin{array}{l}\text { Bioinformática é o estudo da aplicação de técnicas computacionais e matemáticas à geração e } \\
\text { gerenciamento de (bio)informação. Buscando tratar os dados, é necessário desenvolver softwares para, } \\
\text { por exemplo: identificar genes, prever a configuração tridimensional de proteínas, identificar inibidores } \\
\text { de enzimas, organizar e relacionar informação biológica, simular células, agrupar proteínas homólogas, } \\
\text { montar árvores filogenéticas, analisar experimentos de expressão gênica, dentre outras inúmeras } \\
\text { aplicações. }\end{array}$ \\
\hline \multirow{5}{*}{$\begin{array}{l}\text { Engenharia } \\
\text { biomédica }\end{array}$} & $\begin{array}{l}\text { A engenharia biomédica é uma área multidisciplinar que pode ser entendida como a aplicação de métodos } \\
\text { das Ciências Exatas e de Engenharia no campo das Ciências Médicas e Biológicas. É a área da engenharia } \\
\text { que cuida da concepção de equipamentos médicos, biomédicos e odontológicos, voltados para diagnóstico } \\
\text { ou tratamento terapêutico. Pode ser dividida em quatro subáreas: }\end{array}$ \\
\hline & $\begin{array}{l}\text { Bioengenharia: voltada ao desenvolvimento da ciência biomédica, envolve atividades tais como: } \\
\text { bioengenharia cardiovascular; circulação extracorpórea assistida; estimulação interna artificial; órgãos } \\
\text { artificiais; engenharia celular e tecidos artificiais; próteses biomecânicas; e engenharia do sistema } \\
\text { respiratório }\end{array}$ \\
\hline & $\begin{array}{l}\text { Engenharia de reabilitação: objetiva o desenvolvimento de sistemas eletrônicos e mecânicos que } \\
\text { melhorem as condições de vida de deficientes e se concentra basicamente na pesquisa e produção de } \\
\text { equipamentos e próteses }\end{array}$ \\
\hline & $\begin{array}{l}\text { Engenharia médica: direcionada ao estudo, projeto e desenvolvimento de dispositivos, métodos e } \\
\text { equipamentos para finalidades diagnósticas, terapêuticas, de ensino e pesquisa nas áreas de saúde e } \\
\text { biológica. Aplica-se o desenvolvimento de instrumentação e processamento de sinais e dados, ensaios de } \\
\text { produção de equipamentos médicos e de pesquisa (instrumentação - principalmente eletrônica, sensores, } \\
\text { próteses, etc.), destacando-se as seguintes áreas: biotelemetria e sensoriamento remoto de sistemas } \\
\text { biomédicos; instrumentação analógico-digital; e processamento de sinais para a área cardiológica }\end{array}$ \\
\hline & $\begin{array}{l}\text { Engenharia clínica ou hospitalar: voltada às atividades de certificação e ensaios de equipamentos médicos } \\
\text { e às atividades em hospitais, incluindo projetos, adequação e execução de instalações, assessoria em } \\
\text { processos de tomada de decisão na aquisição de equipamentos, treinamento e orientação de equipes de } \\
\text { manutenção }\end{array}$ \\
\hline
\end{tabular}

Fonte: Adaptado de ABDI, 2010. 
Outra área em que se preveem grandes desenvolvimentos é aquela dos materiais e suas tecnologias de processamento que combinem características mecânicas, funcionais, biológicas, farmacêuticas ou mesmo terapêuticas dos materiais. Por exemplo, prevê-se o desenvolvimento de polímeros com memória para clínicas médicas - materiais se transformam em uma forma pré-determinada quando ativados por luz, calor ou campo magnético e podem ser implantados e ativados em qualquer lugar no corpo humano. A primeira dessas tecnologias aparecerá na forma de autossuturas e aparelhos ortodônticos que se ajustam rapidamente.

O desenvolvimento de pinos de titânio para osseointegração é outra área promissora. Inicialmente utilizada em implantes odontológicos, a técnica começou a ser usada em próteses faciais e aponta-se que o grande potencial de aplicação é a utilização de parafusos de titânio em próteses ortopédicas (MARTINS, 2008).

Ainda no âmbito das novas tecnologias crescentemente incorporadas em equipamentos médicos saliente-se a automação. Cada vez mais os novos desenvolvimentos focam equipamentos projetados para operações automatizadas, complexas e de precisão. Estes equipamentos podem executar uma variedade de aplicações, incluindo a montagem de dispositivos médicos e de preparação de receitas, automação de laboratórios, maquinário de monitoração, manuseio de materiais, embalagem e montagem eletrônica (PHARMACEUTICAL DRUG MANUFACTURERS, 2011).

Um workshop realizado em 2008 pela Food and Drug Administration (FDA) teve como objetivo a identificação de tendências na indústria de equipamentos médicos no que se refere às principais tecnologias e produtos relacionados com potencial de desenvolvimento significativo em uma década. Os principais resultados obtidos são apresentados na tabela 9.

A intensificação das pressões para a redução dos custos dos sistemas de saúde, uma vez que os mesmos precisam incorporar parcelas cada vez maiores da população que crescentemente se torna mais longeva, e o caráter cada vez mais preventivo da medicina, reduzindo tempos de internação e recuperação, vêm estimulando o desenvolvimento de novas tecnologias que possibilitem processos de recuperação nas próprias residências, apoiados pelo desenvolvimento da telemedicina. Neste contexto, o incentivo a novos procedimentos clínicos minimamente invasivos e menos agressivos, a personalização do atendimento e a monitoração remota levam a potencializar a miniaturização e o desenvolvimento de dispositivos inteligentes, privilegiando a convergência entre os diferentes campos do conhecimento como as tecnologias da informação e comunicação, a nanotecnologia e os novos materiais. Tal sinergia viabilizará alcançar benefícios clínicos sem precedentes (ARABE, 2003). 
Tabela 09. Inovações em equipamentos médicos: tendências 2010-2020

\begin{tabular}{|c|c|}
\hline Tecnologia & Produto \\
\hline $\begin{array}{l}\text { Dispositivos computadorizados e } \\
\text { sistemas de informação }\end{array}$ & $\begin{array}{l}\text { - Registros eletrônicos integrados de pacientes } \\
\text { - Sistemas de diagnóstico computadorizados } \\
\text { - Sistemas médicos baseados na internet } \\
\text { - Sistemas de realidade virtual para treinamento e outras aplicações } \\
\text { - Redes de dispositivos }\end{array}$ \\
\hline Sistemas e produtos robóticos & $\begin{array}{l}\text { - Sistemas cirúrgicos robóticos } \\
\text { - Próteses robóticas }\end{array}$ \\
\hline Sistemas e produtos sem fio & - Sistemas avançados de identificação de rádio frequência (RFID) \\
\hline $\begin{array}{l}\text { Órgãos artificiais e produtos } \\
\text { relacionados }\end{array}$ & $\begin{array}{l}\text { - Engenharia de tecidos } \\
\text { - Dispositivos neurossensoriais } \\
\text { - Produtos para monitoração da glicose } \\
\text { - Produtos para eletroestimulação } \\
\text { - Novos tipos de bombas e de sistemas de liberação de insulina } \\
\text { - Próteses avançadas de membros } \\
\text { - Novos tipos de stents } \\
\text { - Substituição de articulações }\end{array}$ \\
\hline Dispositivos combinados & - Sistemas avançados de liberação de drogas \\
\hline $\begin{array}{l}\text { Sistemas e dispositivos de } \\
\text { imagem }\end{array}$ & $\begin{array}{l}\text { - Sistema de terapia guiados por imagem } \\
\text { - Sistemas avançados de ultrassom } \\
\text { - Sistemas avançados óticos } \\
\text { - Sistemas avançados de ressonância magnética }\end{array}$ \\
\hline Produtos fotônicos & $\begin{array}{l}\text { - Produtos para diagnóstico ótico } \\
\text { - Dispositivos terapêuticos óticos }\end{array}$ \\
\hline $\begin{array}{l}\text { Produtos terapêuticos } \\
\text { minimamente invasivos }\end{array}$ & $\begin{array}{l}\text { - Novos implantes } \\
\text { - Novos sistemas de radioterapia }\end{array}$ \\
\hline Produtos de atenção domiciliar & $\begin{array}{l}\text { - Novos tipos de sensores domésticos } \\
\text { - Casas inteligentes }\end{array}$ \\
\hline $\begin{array}{l}\text { Tecnologias de genômica, } \\
\text { proteômica, metabólica e } \\
\text { epigenômica }\end{array}$ & - Produtos de diagnóstico genético \\
\hline Tecnologia de sensores & - Novos sensores \\
\hline $\begin{array}{l}\text { Sistemas de monitoramento de } \\
\text { pacientes }\end{array}$ & $\begin{array}{l}\text { - Sistemas de monitoramento remoto } \\
\text { - Produtos para exames médicos no local de diagnóstico/tratamento }\end{array}$ \\
\hline Outros & - Dispositos MEMS (Micro-Electro-Mechanical Systems) e minissensores \\
\hline
\end{tabular}

Fonte: Herman \& Devey, 2010. 
Em um cenário de longo prazo a expectativa é de que os investimentos na indústria de equipamentos e materiais médico-hospitalares e odontológicos brasileira promovam impactos profundos no que tange à ampliação da competitividade da mesma, com adensamento tecnológico de seus produtos e processos e, concomitantemente, aumento do dispêndio em atividades inovativas em equipamentos e materiais estratégicos, com efeitos positivos em termos de sua participação no PIB, de crescimento do emprego e da renda, ampliação e diversificação das exportações e de redução do déficit comercial.

A indústria de equipamentos e materiais médico-hospitalares e odontológicos, claramente, se constitui em uma área estratégica no que se refere ao seu potencial intrínseco de promoção do adensamento do sistema nacional de inovação e de ampliação da competitividade da indústria como um todo. Constituise em uma indústria portadora do futuro, por ser fonte geradora de inovações, por demandar e incorporar fortemente avanços tecnológicos oriundos de outras indústrias tradicionalmente inovadoras, a exemplo da microeletrônica, mecânica de precisão, química e novos materiais, e por suas inter-relações dinâmicas tanto no interior do Complexo Econômico-Industrial da Saúde em particular, como no âmbito da atividade econômica como um todo. Constitui-se, igualmente, em área estratégica no âmbito da saúde ao ser responsável pela oferta permanente de novos de equipamentos e materiais que propiciem aumento da qualidade dos padrões de tratamento e diagnóstico no sentido de serem mais efetivos, mais rápidos, mais seguros e menos invasivos.

No que se refere à identificação de equipamentos prioritários do ponto de vista de seu desenvolvimento nacional destacam-se exemplos de equipamentos para os quais se necessita construir competências ${ }^{7}$, quais sejam:

- Chips dedicados para indústria de equipamentos hospitalares, que podem ser utilizados em inúmeros equipamentos eletromédicos;

- Hemodialisadores: filtros utilizados em hemodiálise;

- Artigos e instrumentos cirúrgicos (instrumental) fabricados a partir de plásticos de engenharia - e não pelo método tradicional de indústrias metalúrgicas;

- Equipamentos automatizados para diagnóstico;

- Imagens médicas: receptores, aparelhos de ultrassom, radiologia digital;

- Tecnologia de materiais.

7 Os mesmos foram definidos a partir de discussões realizadas com a ABIMO. 
Esta aposta leva em conta tanto o perfil tecnológico e industrial atual das empresas que compõem a indústria de equipamentos e materiais médico-hospitalares e odontológicos no Brasil, como o caráter cumulativo do aprendizado, isto é, o aspecto path dependent das trajetórias tecnológicas. Leva-se também em consideração que as iniciativas governamentais de apoio ao seu desenvolvimento, desenhadas a partir de agora, gerarão frutos efetivos a longo prazo. É justamente a promoção à adoção de trajetórias tecnológicas cada vez mais densas por parte das empresas, que as conduzirão à construção de vantagens competitivas em determinados nichos de mercado, em um futuro desejável de longo prazo. 


\section{4 | REFERÊNCIAS BIBLIOGRÁFICAS}

AGÊNCIA BRASILEIRA DE DESENVOLVIMENTO INDUSTRIAL (ABDI). Relatório de acompanhamento setorial - Complexo da Saúde: equipamentos médicos, hospitalares e odontológicos equipamentos médicos, hospitalares e odontológicos. Volume IV. Disponível em: <www.abdi.com.br/Estudo/Equipamentos\%20M\%C3\%A9dicos\%20-\%20\%20dez2009.pdf>. Acesso em: 20 out. 2011. (2009a).

AGÊNCIA BRASILEIRA DE DESENVOLVIMENTO INDUSTRIAL (ABDI). Estudo prospectivo: cadeia de equipamentos médicos, hospitalares e odontológicos. Série Cadernos da Indústria ABDI. Disponível em: <www.abdi.com.br/?q=system/files/Estudo+prospectivo+Equipamento+Medi co--hospitalar+e+Odontologico_0.pdf>. Acesso em: 20 out. 2010. (2009b).

AGÊNCIA BRASILEIRA DE DESENVOLVIMENTO INDUSTRIAL (ABDI). Sistemas Aplicados a Saúde Humana. Cadernos temáticos TICs - 4. Brasília: ABDI, 2010.

ALBUQUERQUE EM, CASSIOLATO, JE. As especificidades do sistema de inovação do setor saúde: uma resenha da literatura como introdução a uma discussão sobre o caso brasileiro. Belo Horizonte: Federação de Sociedades de Biologia Experimental; 2000. (Estudos FeSBE, 1).

ARABE, K. The future of the medical industry. Disponível em: http://news.thomasnet.com/ IMT/archives/2003/06/the_future_of_t.html. 2003.

ASSOCIAÇÃO BRASILEIRA DA INDÚSTRIA DE ARTIGOS E EQUIPAMENTOS MÉDICOS, ODONTOLÓGICOS E HOSPITALARES E DE LABORATÓRIO (ABIMO). Disponível em: <www.abimo. org.br/default_interno.asp.>. Acesso em: 20 out. 2010.

BANCO NACIONAL DE DESENVOLVIMENTO ECONÔMICO E SOCIAL (BNDES). Sítio Eletrônico: http://www.bndes.gov.br. 2010.

BORGES, A. S. Envelhecimento e deficiência na região metropolitana do Rio de Janeiro: o que esperar do futuro? Disponível em: http://www.abep.nepo.unicamp.br/encontro2008/docsPDF/ ABEP2008_1063.pdf. 2008.

BRASIL. MINISTÉRIO DA SAÚDE. Mais Saúde: direito de todos - 2008-2011. 5. ed. Brasília, 2007. 128 p. Disponível em: <http://bvsms.saude.gov.br/bvs/pacsaude/programa.php>. Acesso em: 20 out. 2011.

BRASIL. MINISTÉRIO DA SAÚDE. Portaria $\mathrm{n}^{\circ}$ 1284, de 26 de maio de 2010. Altera o anexo a Portaria n 978/GM/MS, de 16 de maio de 2008. Brasília: Ministério da Saúde. Página web: http:// www.saude.mt.gov.br/upload/legislacao/1284-\%5B3573-080610-SES-MT\%5D.pdf

BRASIL. MINISTÉRIO DO DESENVOLVIMENTO, INDÚSTRIA E COMÉRCIO EXTERIOR. Política de Desenvolvimento Produtivo (PDP). Brasília. Disponível em http://www.mdic.gov.br/pdp/ arquivos/destswf1224095287. Acesso em 2008. (Brasil, 2008a)

BRASIL. MINISTÉRIO DA SAÚDE. Gabinete do Ministro. Portaria No 1.942, de 17 de setembro de 2008. Aprova o Regimento Interno do Grupo Executivo do Complexo Industrial da Saúde GECIS e institui o Fórum Permanente de Articulação com a Sociedade Civil. (Brasil, 2008b)

BRASIL. MINISTÉRIO DA SAÚDE. Portaria n 978 de 16 de maio de 2008. Brasília: Ministério da Saúde. Página web: ftp://ftp.saude.sp.gov.br/ftpsessp/bibliote/informe_eletronico/2008/iels. maio.08/iels97/U_PT-MS-GM-978-REP_160508.pdf. (Brasil, 2008c) 
BRASIL. PRESIDÊNCIA DA REPÚBLICA. Diretrizes de política industrial, tecnológica e de comércio exterior. Brasília. 2003. Disponível em: <www.camara-e.net/_upload/20031126Diretrizes.pdf>. Acesso em: 20 dez. 2011.

BRASIL. PRESIDÊNCIA DA REPÚBLICA. Casa Civil. Decreto No 5.563, de 11 de outubro de 2005. Disponível em: http://www.planalto.gov.br/ccivil_03/_Ato2004-2006/2005/Decreto/D5563.htm.

BRASIL. PRESIDÊNCIA DA REPÚBLICA. Plano de Inovação do Brasil. Plano Brasil Maior. Inovar para competir. Competir para crescer: plano 2011/2014. Disponível em: <www.brasilmaior.mdic. gov.br/wp-content/uploads/cartilha_brasilmaior.pdf>. Acesso em: 20 out. 2011.

BUSINESS WIRE. Research and markets: investment and acquisitions. Trends in medical equipment market 2011. Disponível em: http://www.businesswire.com/news/ home/20110322006938/en/Research-Markets-Investment-Acquisitions-Trends-MedicalEquipment.

BUTTON, VLSN; OLIVEIRA, EJV. Uma estratégia de desenvolvimento para o sistema nacional de inovação de produtos médicos. Rev Bras Eng Biomed. 2012;28(2):124-39.

CASTRO, M, H. L. A utilização de novas tecnologias e o aumento de custos com a atenção a saúde: uma análise dos países desenvolvidos. In: I Jornada de Economia da Saúde, São Leopoldo. 2003

CECOTOSTI, K. Negócios: Philips adquire VMI Sistemas Médicos e reforça posicionamento no mercado de raios X. Disponível em: <http://saudeweb.com.br/3959/negocios-philips-adquirevmi-sistemas-medicos-e-reforca-posicionamento-no-mercado-de-raio-x/>. Acesso em: 05 jun. 2007.

DEPARTMENT FOR BUSINESS INNOVATION \& SKILLS. (BIS) The 2009 R\&D Scoreboard (2010). UK, Department for Business, Innovation \& Skills,.Página web: http://www.innovation.gov.uk.

ESPICOM BUSINESS INTELLIGENCE (ED). The World Medical Markets Fact Book 2010. Great Britain: Espicon Business Intelligence. 2010. 286 p.

ETTLINGER, M. The future of medical devices: 2025 A.D. Disponível em: http://www.devicelink. com/mpmn/archive/05/07/021.html. 2005.

EXPORTMED BRAZIL. Medical devices market opportunities for U.S. small and medium-sized enterprises. Washington: U.S. Department Of Commerce; International Trade Administration, 2004. 63 p.

FINANCIADORA DE ESTUDOS E PROJETOS (FINEP). Sitio Eletrônico: http://www.finep.gov.br. 2010.

FRANÇA, A. Disputa acirrada em equipamentos médicos. São Paulo: Gazeta Mercantil, 09 jun. 2008.

FURTADO, J. (2001). A indústria de equipamentos médico-hospitalares: elementos para uma caracterização da sua dimensão internacional. In: NEGRI, B.; DI GIOVANNI, G. Brasil: radiografia da saúde. Campinas, UNICAMP, 2001. p.45-61.

GADELHA, C. A. G. (2007). Complexo econômico-industrial da saúde: produtos e insumos estratégicos para as políticas e programas de saúde. In: Conselho Nacional de Secretários de Saúde. Ciência e Tecnologia em Saúde. Cap. 4. Brasília: CONASS, 2007. 
GADELHA, CAG; MALDONADO, JMSV; VARGAS, MA; BARBOSA, P \&COSTA, LS. A dinâmica do sistema produtivo da saúde: inovação e complexo econômico-industrial. Rio de Janeiro: Ed. Fiocruz, 2012; 221p.

GELLERMANN, L.; LEONARDO, F. 3M adquire divisão de negócios da POMP. [S.1.]: Companhia de Notícias, 2006. 2 p. Disponível em: <www.3m.com/intl/br/sala_de_imprensa/download/OHES_ aquisicaoPOMP.pdf>. Acesso em: 09 jun. 2006.

GOMES, L. C. N. Estratégias de produção na indústria de equipamentos médicos de diagnóstico por imagem: uma análise da ressonância magnética. Revista Produção / UFSC. Florianópolis, 2007.

GUTIERREZ, R. M. V.; ALEXANDRE, P. V. M. Complexo industrial da saúde: uma introdução ao setor de insumos e equipamentos de uso médico. BNDES Setorial, Rio de Janeiro, n. 19, p. 119155, 2004.

HERMAN, A. \& DEVEY, G. B. (2010). Future trends in medical device technologies: a ten-year forecast. USA: Food and Drug Administration (FDA).

INSTITUTO BRASILEIRO DE GEOGRAFIA E ESTATÍSTICA (IBGE). Pesquisa Industrial de Inovação Tecnológica - PINTEC. 2003, 2005, 2007.

INSTITUTO BRASILEIRO DE GEOGRAFIA E ESTATÍSTICA (IBGE). Séries estatísticas. 2011. Disponível em http://seriesestatisticas.ibge.gov.br/.

INSTITUTO DE ESTUDOS E MARKETING INDUSTRIAL (IEMI). Estudo setorial da indústria de equipamentos odonto-médico-hospitalar e laboratorial no Brasil. São Paulo: Instituto de Estudos e Marketing Industrial (IEMI); Associação Brasileira da Indústria de Artigos e Equipamentos Médicos, Odontológicos (Abimo), 2010.

INSTITUTO NACIONAL DE METROLOGIA, NORMALIZAÇÃO E QUALIDADE INDUSTRIAL (INMETRO). 2010. Disponível em: http://www.inmetro.gov.br.

LEÃO, R.; OLIVEIRA, E.; ALBORNOZ, L. Estudo setorial: setor de equipamentos e materiais de uso em saúde. Brasília: Secretaria de Ciência, Tecnologia e Insumos Estratégicos; Departamento de Economia da Saúde; Coordenação Geral de Economia da Saúde, 2008.

MALDONADO, J. Equipamentos Médicos (Documento Setorial). Projeto Perspectivas do Investimento no Brasil; Perspectivas do Investimento em Saúde. Sistema Produtivo 11. Instituto de Economia/ UFRJ e Instituto de Economiaq/UNICAMP, 2007. Disponível em http://www. revistainonline.com.br/ler_noticia_saude.asp?noticia=421. (2007a)

MALDONADO, J. Equipamentos Médicos (Documento Setorial). Projeto Perspectivas do Investimento no Brasil; Perspectivas do Investimento em Saúde. Sistema Produtivo 11. Instituto de Economia/ UFRJ e Instituto de Economiaq/UNICAMP, 2007. Disponível em http://www. santistaclass.com.br/noticias-20070413-nanotecnologia.htm, 13/04/07. (2007b)

MANFREDINI, M. A. Características da indústria de equipamentos odontológicos e de produtos para higiene bucal no Brasil entre 1990 e 2000. Dissertação (Mestrado). Programa de Pósgraduação em Ciências. Coordenadoria de Controle de Doenças da Secretaria de Saúde de São Paulo. São Paulo, 2006.

MARTINS, A. Philips Brasil anuncia aquisição de empresa de TI em saúde. Disponível em: <www.saudebusinessweb.com.br/noticias/index.asp?cod=66613>. Acesso em: 25 mar. 2010. 
MARTINS, R. Dos aviões para o corpo humano. São Paulo: Carta Capital, 2008.

MITO, T. Opinião: mercado brasileiro de diagnóstico por imagem. Disponível em: <www. saudebusinessweb.com.br/noticias/index.asp?cod=49072>. Acesso em: 24 jun. 2008.

NASCIMENTO, I. Philips implanta novo modelo de negócio no mercado brasileiro. São Paulo: Gazeta Mercantil. Disponível em: http://www.indexet. Gazetamercantil.com.br/ arquivo/2008/03/19/50/Philips-implanta-novo-modelo-de-negocio-no-mercado-brasileiro. html. Acesso em: 19 mar 2008.

REDE NACIONAL DE ENSINO E PESQUISA (RNP). Rede Universitária de Telemedicina (Rute). O que é Telemedicina. Disponível em: http://rute.rnp.br/sobre/telemedicina. 2008

PAMMOLLI, F. et al. Medical devices competitiveness and impact on public health expenditure. CERM - Competitiveness, Markets and Regulation. Rome, 2005.

PARTNERING NEWS. Emerging trends in the medical equipment industry. Disponível em: $<$ http://ebdgroup.com/partneringnews/2010/05/emerging-trends-in-the-medical-equipment-industry>. Acesso em: 20 out. 2011.

PHARMACEUTICAL DRUG MANUFACTURERS. Medical equipment industry: the new trends and focuses. Disponível em: <www.pharmaceutical--drug-manufacturers.com/articles/medicalequipment-trends.html>. Acesso em: 20 out. 2011.

PIERONI, J. P.; REIS, C.; SOUZA, J. O. B. A indústria de equipamentos e materiais médicos, hospitalares e odontológicos: uma proposta de atuação do BNDES. Rio de Janeiro: BNDES Setorial, 2010. p. 185-226.

POLETTO, F.; POHLMANN, A. R.; GUTERRES, S. S. Uma pequena grande revolução. Ciência Hoje, Rio de Janeiro, v. 43, n. 255, 2008.

POLONI, G. GE inaugura em MG primeira fábrica de equipamentos médicos na AL. Economia, 2010. Disponível em: <economia.ig.com.br/empresas/industria/ ge+inaugura+em+mg+primeira+fabrica+de+equipamentos+medicos+na+al/n1237724722104. html>. Acesso em: 21 jul. 2010.

REHEM, T.C.M.S. B.; TRAD, L. A.B. Assistência domiciliar em saúde: subsídios para um projeto de atenção básica brasileira. Ciênc. Saúde Coletiva vol.10 suppl: 231-42. Rio de Janeiro Sept./Dec. 2005

SANTANA, P. Assistência domiciliar compete com hospitalar? Saúde Business Web. Especial Homecare, 31 de outubro de 2008 Disponível em: http://www.saudebusinessweb.com.br/ noticias/index.asp?cod=52628. Acesso em: 31 out. 2008.

SCHRAMM, J. M. A. et al. Transição epidemiológica e o estudo de carga de doença no Brasil. Ciência \& Saúde Coletiva, Rio de Janeiro, v. 9, n. 4, p. 897-908, 2004.

SELAN, B., PORTO, G. KANNEBLEY JÚNIOR, S. Parque tecnológico de Ribeirão Preto. Relatório Setorial de Inovação Tecnológica: Indústria de Produtos e Equipamentos Médico-Hospitalares e Odontológicos Brasileira. Ribeirão Preto: FIPASE. 2007.

SOUZA, V. Philips compra Wheb sistemas. Saúde Web. Notícias em destaque. 13 set. 2010. Disponível em: <http://saudeweb.com.br/15879/philips--compra-wheb-sistemas>. Acesso em: 20 out. 2011. 
SOUZA, C. Philips anuncia a aquisição da Dixtal. Saúde Web. Disponível em: <www. saudebusinessweb.com. br/noticias/index.asp?cod=47895>. Acesso em: 13 maio 2008.

TEECE, D. Strategies for capturing the financial benefits from technological innovation. In: Rosenberg, N., Landau, R., Mowery, D. (eds). Technology and the Wealth of Nations. Stanford: Stanford University Press, 1992.

VIANA, A. L. et al. (2011). Complexo produtivo da saúde, desenvolvimento e incorporação de tecnologias. In: IBAÑEZ, N.; ELIAS, P.; SEIXAS, P. (Org.). Política e gestão pública em saúde. São Paulo: Hucitec Editora — Cealag, 2011. 816p.

WORLD HEALTH ORGANIZATION (WHO) Statistics. Página web: http://www.who.int/whosis/ whostat/EN_WHS2011_Full.pdf. 2011. 